\title{
17. LOWER JARAMILLO POLARITY TRANSITION RECORDS FROM THE EQUATORIAL ATLANTIC AND INDIAN OCEANS ${ }^{1}$
}

\author{
Jeff Gee, ${ }^{2}$ Lisa Tauxe, ${ }^{2}$ and Eunjoo Barg ${ }^{2}$
}

\begin{abstract}
Two records of the geomagnetic polarity transition at the beginning of the Jaramillo Subchron ( $0.97 \mathrm{Ma})$ have been obtained from sediments in the equatorial Atlantic (Leg 108, Site $665 ; 2.95^{\circ} \mathrm{N}, 340.33^{\circ} \mathrm{E}$ ) and Indian (Leg 121 , Site $758 ; 5.38^{\circ} \mathrm{N}, 90.35^{\circ} \mathrm{E}$ ) oceans. Both cores yielded high-quality magnetostratigraphic results; however, the relatively low sedimentation rates, the weak magnetizations, and complex demagnetization behavior of some transitional samples suggest that the record of the transitional field behavior may be less reliable. In addition, variations in grain size preclude reliable paleointensity determinations although the remanence in both cores is apparently dominated by magnetite. Despite these possible complications, the two cores yield transitional paths that are neither far-sided nor near-sided. Together with published records that meet minimum reliability standards, the two equatorial records presented here suggest that the lower Jaramillo transitional field morphology was significantly nonaxisymmetric. The mean normal and reversed inclinations from both cores deviate from the inclination expected from a geocentric axial dipole, as noted in virtually all marine sediment cores. The observed inclinations provide further support for a polarity-dependent nondipole contribution to the time-averaged field.
\end{abstract}

\section{INTRODUCTION}

Since the documentation of polarity reversals of the geomagnetic field (Cox et al., 1963, 1964), the processes responsible for reversals and characterization of the transitional field have been areas of active research. As transitional records have become more numerous, models of transitional field behavior have also increased both in number and complexity (see review in Bogue and Hoffman, 1987). The noncoincidence of virtual geomagnetic pole (VGP) paths from the first two records of the Matuyama/Brunhes transition led to the early rejection of a simple dipole model for the transitional field (Hillhouse and Cox, 1976). Hillhouse and Cox suggested that these records might reflect the dominance of the standing nondipole field during the decay and subsequent regeneration of the dipole. The similarity of inclination and intensity variations for successive transitions provides support for this standing field model (e.g., Clement and Kent, 1985).

Deterministic models involving low-order zonal components, corresponding to initiation of the reversal in a particular zone with subsequent flooding through the remainder of the core, have also been advanced for transitional behavior (Hoffman, 1977; Hoffman and Fuller, 1978; Williams and Fuller, 1981). Transitional fields dominated by axisymmetric terms generate longitudinally confined VGP paths centered on either the site longitude (nearsided) or its antipode (far-sided). The particular path is dependent on the site latitude, sign of the dominant zonal components, and the sense of the reversal. Antipodal transition paths during successive reversals (e.g., Valet et al., 1988a) suggest a similarity of the reversal process through time; however, transitional paths commonly lack the strong site dependence required by purely zonal models. Incorporation of nonzonal terms allows modeling of transition records that are neither near-sided nor far-sided (Williams et al., 1988; Hoffman, 1979). More recently, Constable (1990) has shown that many features observed in transitional records may be reproduced by decay of the dipole field combined

\footnotetext{
'Weissel, J., Peirce, J., Taylor, E., Alt, J., et al., 1991. Proc. ODP, Sci. Results, 121: College Station, TX (Ocean Drilling Program).

${ }^{2}$ Scripps Institution of Oceanography, La Jolla, CA 92093, U.S.A.
}

with random fluctuations of a model nondipole field based on the statistical properties of the present geomagnetic field (Constable and Parker, 1988).

The increasing number of polarity transition records provides constraints for at least the deterministic models of transitional field behavior. In particular, successive reversal records from a single location which exhibit antipodal VGP paths support the flooding model (Hoffman, 1977), whereas mirror-image inclination and intensity variations suggest the dominance of standing fields during transition, as suggested by Hillhouse and Cox (1976). Successive records also provide information on the stability of the reversal process through time (e.g., Valet et al., 1988a). Equally important are multiple records of the same reversal from widely distributed localities, by which the harmonic content of the reversal may, to some extent, be constrained. Deep-sea sediment records from the last few million years are particularly well suited to this end because they are readily assigned to a particular transition using magnetostratigraphic and/or biostratigraphic control and because they provide the opportunity for good global coverage. Marine sediments have the additional advantage of yielding a continuous, albeit smoothed, record of geomagnetic field behavior.

Of the recent transitions, the Matuyama/Brunhes has been the most extensively studied reversal (e.g., Hoffman, 1982). In contrast, only a few records, of variable quality, of the Pleistocene lower Jaramillo polarity transition have been obtained: nine from the Northern Hemisphere and two from the Southern Hemisphere (Table 1). We present transitional records from two equatorial deep-sea sediment cores from the Indian Ocean (Leg 121, Hole $758 \mathrm{~B} ; 5.38^{\circ} \mathrm{N}, 90.35^{\circ} \mathrm{E}$ ) and the Atlantic Ocean (Leg 108 , Hole $\left.665 \mathrm{~A} ; 2.95^{\circ} \mathrm{N}, 340.33^{\circ} \mathrm{E}\right)$. These two equatorial records, together with published records that meet minimum reliability criteria (Valet et al., 1988b), constitute two latitudinal transects that provide information about the behavior of the geomagnetic field during the onset of the Jaramillo Subchron (0.97 Ma).

\section{METHODS}

The magnetostratigraphy of sediments from Site 665 is discussed in Tauxe et al. (1989) and details of the Site 758 PliocenePleistocene section are reviewed in Peirce, Weissel, et al. (1989) 
Table 1. Lower Jaramillo polarity transition records.

\begin{tabular}{|c|c|c|c|}
\hline Record & Location & Type of record & Reference \\
\hline Cerveny & $50^{\circ} \mathrm{N}, 20^{\circ} \mathrm{E}$ & Continental sediments & Bucha (1970) \\
\hline Sedlec & $20.48^{\circ} \mathrm{N}, 15.20^{\circ} \mathrm{E}$ & Continental sediments & Bucha (1973) \\
\hline K7501 & $37.37^{\circ} \mathrm{N}, 180.40^{\circ} \mathrm{E}$ & Deep-sea sediments & Hammond et al. (1979) \\
\hline K7502 & $38.60^{\circ} \mathrm{N}, 179.35^{\circ} \mathrm{E}$ & Deep-sea sediments & Hammond et al. (1979) \\
\hline Adzhidere & $39.50^{\circ} \mathrm{N}, 54.50^{\circ} \mathrm{E}$ & Continental sediments & Gurarii (1981) \\
\hline Monzhukly & $39.50^{\circ} \mathrm{N}, 54.50^{\circ} \mathrm{E}$ & Continental sediments & Gurarii (1981) \\
\hline RC 14-14 & $31.91^{\circ} \mathrm{S}, 59.97^{\circ} \mathrm{E}$ & Deep-sea sediments & $\begin{array}{l}\text { Clement and Kent (1984a); } \\
\text { Opdyke et al. (1973) }\end{array}$ \\
\hline Turkmenia & $41.00^{\circ} \mathrm{N}, 46.50^{\circ} \mathrm{E}$ & Continental sediments & Petrova and Rassanova (1985) \\
\hline K781030 & $18.90^{\circ} \mathrm{N}, 199.60^{\circ} \mathrm{E}$ & Deep-sea sediments & $\begin{array}{l}\text { Herrero-Bervera and Theyer (1986); } \\
\text { Theyer et al. (1985) }\end{array}$ \\
\hline Leg 94, Hole 609B & $48.36^{\circ} \mathrm{N}, 335.77^{\circ} \mathrm{E}$ & Deep-sea sediments & Clement and Kent (1985) \\
\hline Tahiti & $17.67^{\circ} \mathrm{S}, 210.33^{\circ} \mathrm{E}$ & Volcanic rocks & Chauvin et al. (1990) \\
\hline Leg 108 , Hole $665 \mathrm{~A}$ & $2.95^{\circ} \mathrm{N}, 340.33^{\circ} \mathrm{E}$ & Deep-sea sediments & This paper \\
\hline Leg 121 , Hole $758 \mathrm{~B}$ & $5.38^{\circ} \mathrm{N}, 90.35^{\circ} \mathrm{E}$ & Deep-sea sediments & This paper \\
\hline
\end{tabular}

and Farrell and Janecek (this volume). Based on the shipboard magnetostratigraphic results and using the time scale of Berggren et al. (1985), sediment-accumulation rates during the Jaramillo Subchron were estimated to be $2.4 \mathrm{~cm} / 1000 \mathrm{yr}$ at Hole $665 \mathrm{~A}$ and approximately $1.7 \mathrm{~cm} / 1000 \mathrm{yr}$ at Hole $758 \mathrm{~B}$. Detailed oxygen isotope stratigraphy of sediments from Site 758 (Farrell and Janecek, this volume), however, suggests a somewhat higher sedimentation rate (about $2.5 \mathrm{~cm} / 1000 \mathrm{yr}$ ) in the vicinity of the lower Jaramillo transition. Shipboard measurement of archive halves after demagnetization to 5 (Site 665) and $9 \mathrm{mT}$ (Site 758) was used to define the depth of the bottom of the Jaramillo magnetozone. The transitional intervals (Sections 108-665A-3H$6,75-125 \mathrm{~cm} ; 121-758 \mathrm{~B}-2 \mathrm{H}-4,100-150 \mathrm{~cm}$ ) were then sampled using $50-\mathrm{cm}$-long pieces of $2.5 \times 2.5 \mathrm{~cm} \mathrm{U}$ channels developed by Tauxe et al. (1983).

These $U$ channels from Sites 665 and 758 were then demagnetized at 10 and $9 \mathrm{mT}$, respectively, and measured at the Scripps Institution of Oceanography paleomagnetic laboratory using a $2 \mathrm{G}$ Enterprises pass-through cryogenic magnetometer identical to that aboard JOIDES Resolution. Remanence data from the $U$ channels were not deconvolved. Instead, declination, inclination, and intensity values were calculated using an empirically derived effective volume of uniform magnetization for each axis, identical to the procedure used to derive the shipboard directional and intensity records. Measurements of the $U$ channel from Hole $665 \mathrm{~A}$ at $1-\mathrm{cm}$ intervals, after demagnetization to $10 \mathrm{mT}$, are very similar to the coarser shipboard measurements. Likewise, the shore-based measurements $(0.5-\mathrm{cm}$ interval) of the lower Jaramillo transition from Hole $758 \mathrm{~B}$ reproduce the shipboard data for the archive half after identical $(9 \mathrm{mT})$ treatment. Susceptibility of both $U$ channels was also measured at the same spacing as the remanence measurements using a Bartington susceptibility meter.

After measurement with the $2 \mathrm{G}$ magnetometer, the sediment was gently removed from the $U$ channel, cut into thin wafers $(0.5$ $\mathrm{cm}$ for Site $665 ; 0.45 \mathrm{~cm}$ for Site 758 ) using a cheese cutter with a thin stainless-steel wire, and placed into nonmagnetic plastic cubes. The correspondence between $U$ channel and discrete sample data immediately following subsampling is excellent (Figs. 1 and 2). Based on the calculated sedimentation rates, each subsample from the Hole $665 \mathrm{~A}$ record represents approximately $210 \mathrm{yr}$, and wafers from Hole $758 \mathrm{~B}$ record $200-290 \mathrm{yr}$. These discrete samples were measured using a CTF three-axis cryogenic magnetometer, which has a noise level of approximately $5 \times 10^{-12} \mathrm{Am}^{2}$ total moment. For the lower Jaramillo record from Hole $665 \mathrm{~A}$, nearly half of the samples, including all transitional samples, were stepwise demagnetized using a Schonstedt single-axis alternating field (AF) demagnetizer. Samples were typically subjected to double demagnetization at fields $>20 \mathrm{mT}$ (to average out any anhysteretic remanence [ARM] introduced during demagnetiza- tion) until the two measurements diverged by $>30^{\circ}$. A small number of samples was subjected to stepwise thermal demagnetization to $625^{\circ} \mathrm{C}$ using a Schonstedt thermal specimen demagnetizer. The remaining samples from Hole $665 \mathrm{~A}$ were demagnetized at $10 \mathrm{mT}$. All samples from Hole 758B were stepwise AF demagnetized, with double demagnetization at steps of $20 \mathrm{mT}$ and higher. Many of the weakly magnetized transitional samples were doubly demagnetized over the entire range of treatments to ensure that the introduction of spurious ARM components would be detected.

Best-fit directions for samples from both records were calculated using principal component analysis (Kirschvink, 1980),
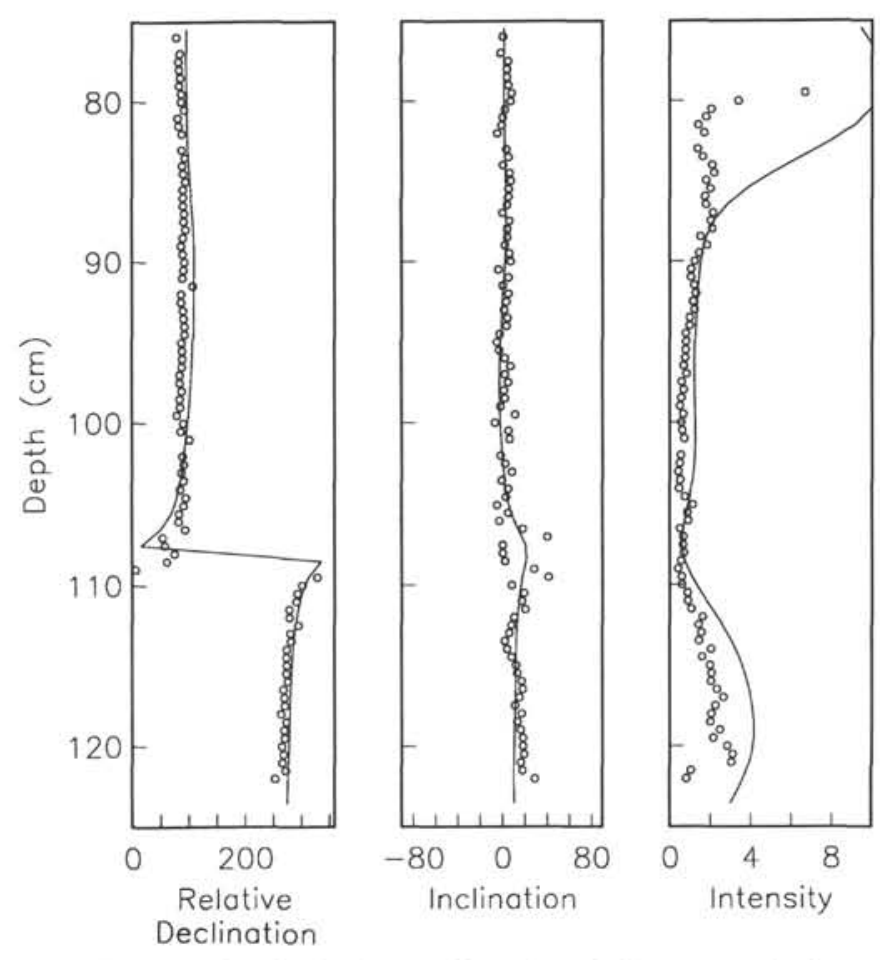

Figure 1. Declination, inclination, and intensity variations across the lower Jaramillo polarity transition from Hole $665 \mathrm{~A}$ after demagnetization at $10 \mathrm{mT}$. The discrete sample data (circles) closely reproduce the magnetization record (lines) from the $U$ channel measured at a 1-cm interval. Depth is relative to the top of Section 108-665A-3H-6. The discrete sample intensities are in units of $10^{-8} \mathrm{Am}^{2}$; declination and inclination in degrees. Both $\mathrm{U}$ channel and discrete sample directions are relative to the fiducial mark on the unoriented core. 


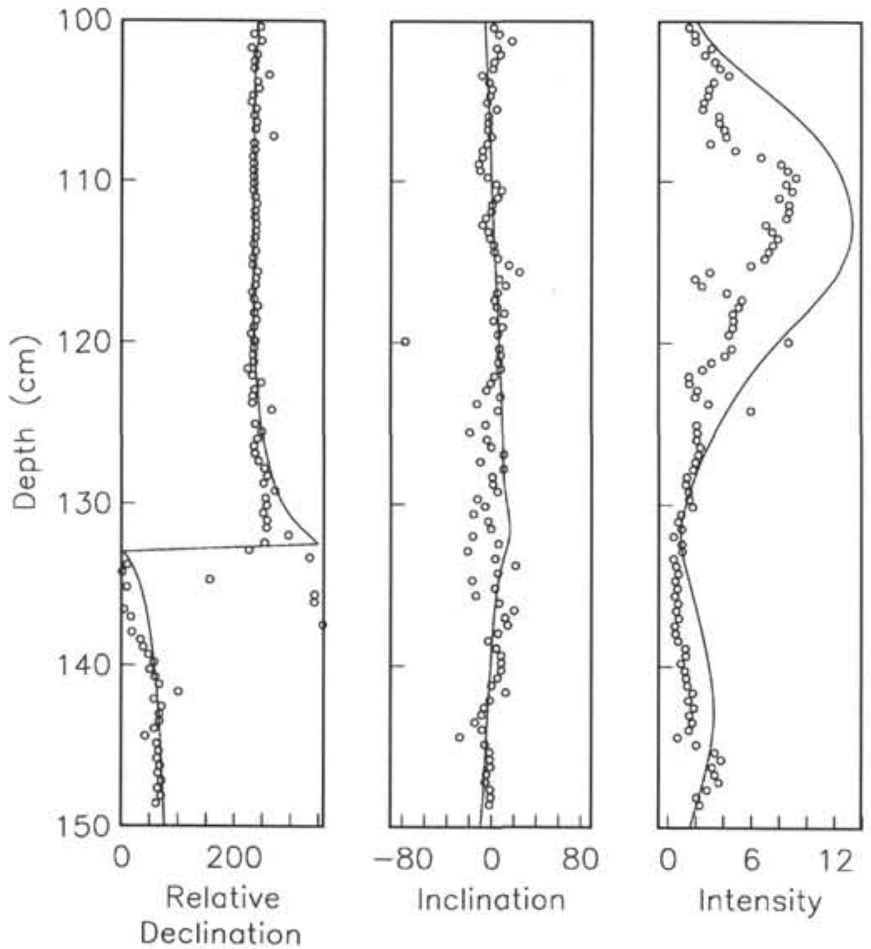

Figure 2. Declination, inclination, and intensity variations across the lower Jaramillo polarity transition from Hole 758B after demagnetization at $9 \mathrm{mT}$. The discrete sample data (circles) closely parallel the magnetization record of the $U$ channel (lines) measured at a $0.5-\mathrm{cm}$ interval. Note the serially correlated inclination variations in the discrete sample data. Depth is relative to the top of Section 121-758B-2H-4. The discrete sample intensities are in units of $10^{-8}$ $\mathrm{Am}^{2}$; declination and inclination in degrees. Both $\mathrm{U}$ channel and discrete sample directions are relative to the fiducial mark on the unoriented core.

both including and excluding the origin (Appendices A and B). Outside the transitional interval the two methods give essentially the same results; however, directions calculated by the two methods result in small $\left(<20^{\circ}\right)$ differences for Site 758 and somewhat larger discrepancies for Site 665 . We have used the principal component directions tied to the origin. Use of the principal components excluding the origin does not significantly alter our conclusions, but a complete list of transitional directions is given in the appendices for comparison. All samples were given an ARM in a peak alternating field of $100 \mathrm{mT}$ and a $0.05-\mathrm{mT}$ bias field. Isothermal remanent magnetization (IRM) acquisition (to peak fields of $0.6 \mathrm{~T}$ ) and decay were measured for selected samples.

\section{RESULTS}

\section{Demagnetization Results}

The range of demagnetization behavior exhibited by sediments from Hole 665A is illustrated in Figure 3. Note that the "NRM" treatment in this and the subsequent figure refers to the initial measurement following subsampling of the $U$ channel and thus corresponds to 10 - and 9-mT demagnetization for samples from Holes 665A and 758B, respectively. Normal and reversed samples outside of the transition zone are nearly univectorial. Thermal demagnetization of a limited number of samples indicates uniformly high maximum unblocking temperatures of less than $600^{\circ} \mathrm{C}$ (Fig. 3A). Low-stability components of magnetization are generally removed by treatments of $10-20 \mathrm{mT}$, and the characteristic magnetization decays linearly to the origin at higher peak fields (Fig. 3B). Samples from the transitional zone are in some cases more than an order of magnitude weaker than nontransitional samples and many exhibit more ambiguous demagnetization behavior. The sample depicted in Figure $3 \mathrm{C}$ is an example of the best transitional demagnetization behavior. The sample yields a relatively well-defined direction from 10 to $22.5 \mathrm{mT}$, but at higher treatments the double demagnetization measurements diverge by more than $30^{\circ}$ and are considered unreliable. The principal component of the linear portion of such samples is classified as a type "A" direction. The transitional sample in Figure 3D undergoes little decrease in intensity and exhibits considerable scatter in successive directions. The interpretation of such diagrams is uncertain. This complex demagnetization behavior may result from antipolar components of similar coercivity; however, the $10-\mathrm{mT}$ step provides the most reasonable compromise between removal of low-stability components and the introduction of spurious (ARM) magnetization. The directions after demagnetization at $10 \mathrm{mT}$ of samples with similar behavior are included in our discussion but are designated as type "B."

Samples from outside the transition interval in Hole 758B have small low-stability components that are generally removed by treatment at $<20 \mathrm{mT}$ (Figs. 4A and 4B). A single sample at a depth of about $120 \mathrm{~cm}$ in Section 121-758B-2H (Fig. 2) was dominated by a large vertical overprint that obscured the characteristic magnetization. As in the Site 665 sediments, demagnetization behavior from the transitional interval in the Hole 758B record includes both relatively well-defined (type A) characteristic directions (Fig. 4C) and more ambiguous sample directions (Fig. 4D). Double demagnetization of weakly magnetic transitional samples, such as the one shown in Figure 4D, indicates that the effects of spurious ARM are significant at peak fields as low as $16 \mathrm{mT}$. Although this ARM prevents precise determination of the characteristic magnetization, we have taken the 9-mT step as representative of the characteristic magnetization direction. Samples with similar behavior are designated type B.

\section{Mineralogy and Grain-Size Variations}

Isothermal remanence acquisition in randomly selected samples from Hole 665A and in samples taken at 5-cm intervals from Hole $758 \mathrm{~B}$ indicates that high-coercivity phases do not contribute significantly to the remanence (Figs. 5A and 5C). Saturation isothermal remanence is essentially achieved in fields of $<0.3 \mathrm{~T}$ in all samples and is consistent with magnetite as the major remanent phase. Maximum unblocking temperatures of less than $600^{\circ} \mathrm{C}$ provide additional evidence of the dominance of magnetite in samples from Hole 665A.

Anhysteretic remanence commonly provides an analog to the NRM in sediments where magnetite is the dominant magnetic phase, and in such cases the ratio of NRM/ARM may give an estimate of paleointensity variations (Levi and Banerjee, 1976). Unfortunately, comparison of ARM and NRM stability to alternating field demagnetization indicates that ARM is not systematically similar to NRM for samples from either Hole $665 \mathrm{~A}$ or Hole 758B (Figs. 5B and 5D). Similarly, comparison of low field susceptibility vs. ARM intensity for sediments from Hole $665 \mathrm{~A}$ reveals a high degree of scatter, suggesting significant downcore variations in magnetic grain size (King et al., 1983).

Figure 6 further illustrates the difficulty in estimating relative paleointensity from the sediments from Hole 758B. ARM intensity varies by nearly an order of magnitude and closely resembles the variations in NRM intensity. The susceptibility $(\chi)$ record shown was measured on the $U$ channel and thus is somewhat smoothed; however, the observed variations are of much longer wavelength and imply significant downcore differences in grain size. The variation in $\chi_{\text {ARM }}$ (the ratio of the ARM to the bias field, where both terms are expressed in $\mathrm{A} / \mathrm{m}$ ) with volume susceptibil- 
A $\quad 108-665 \mathrm{~A}-3 \mathrm{~h}-6,77.5 \mathrm{~cm}$

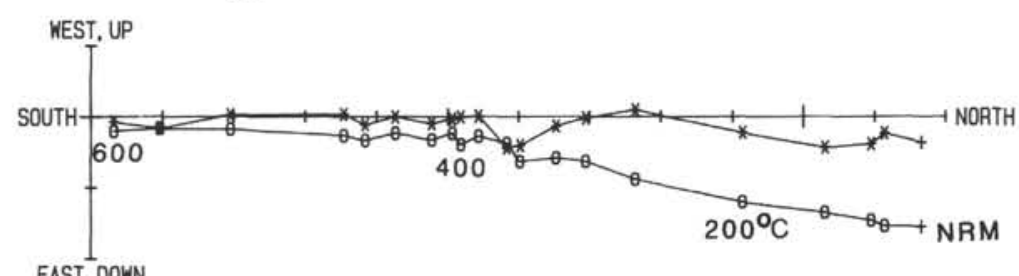

EAST, DOKN

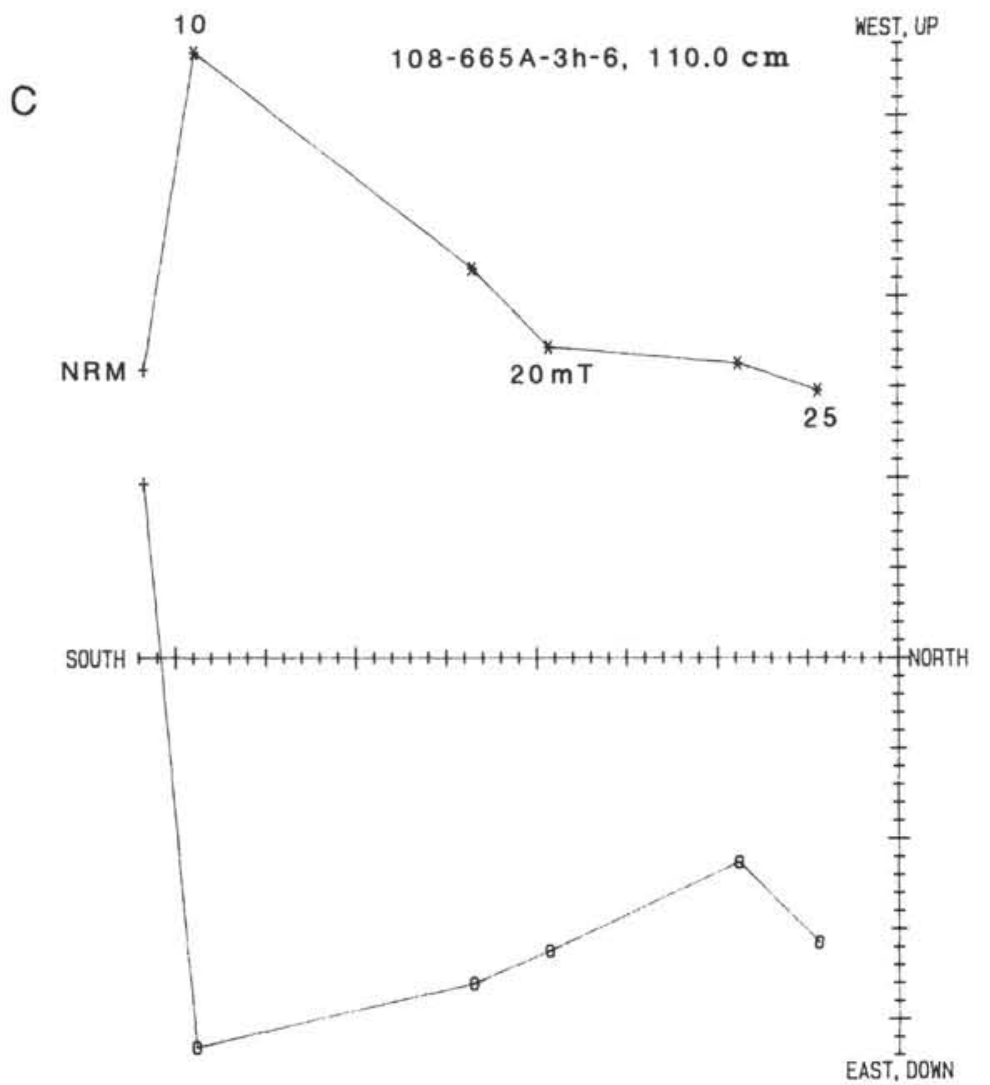

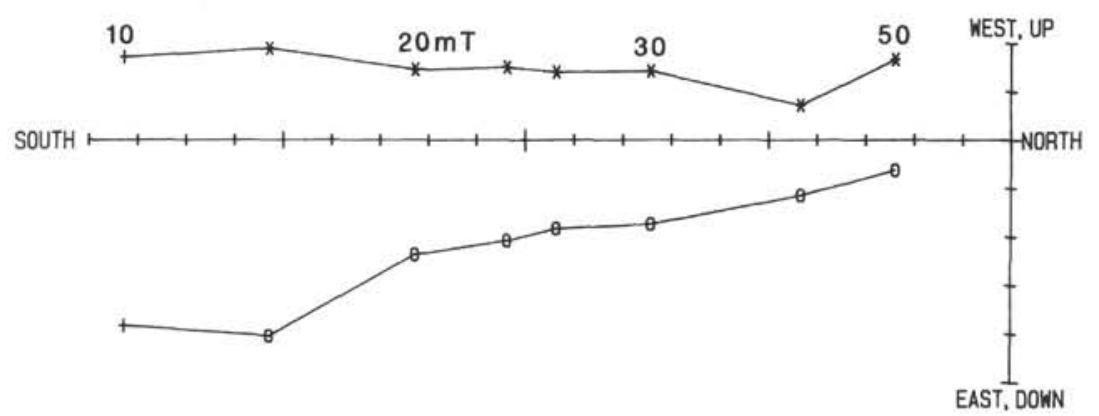

D

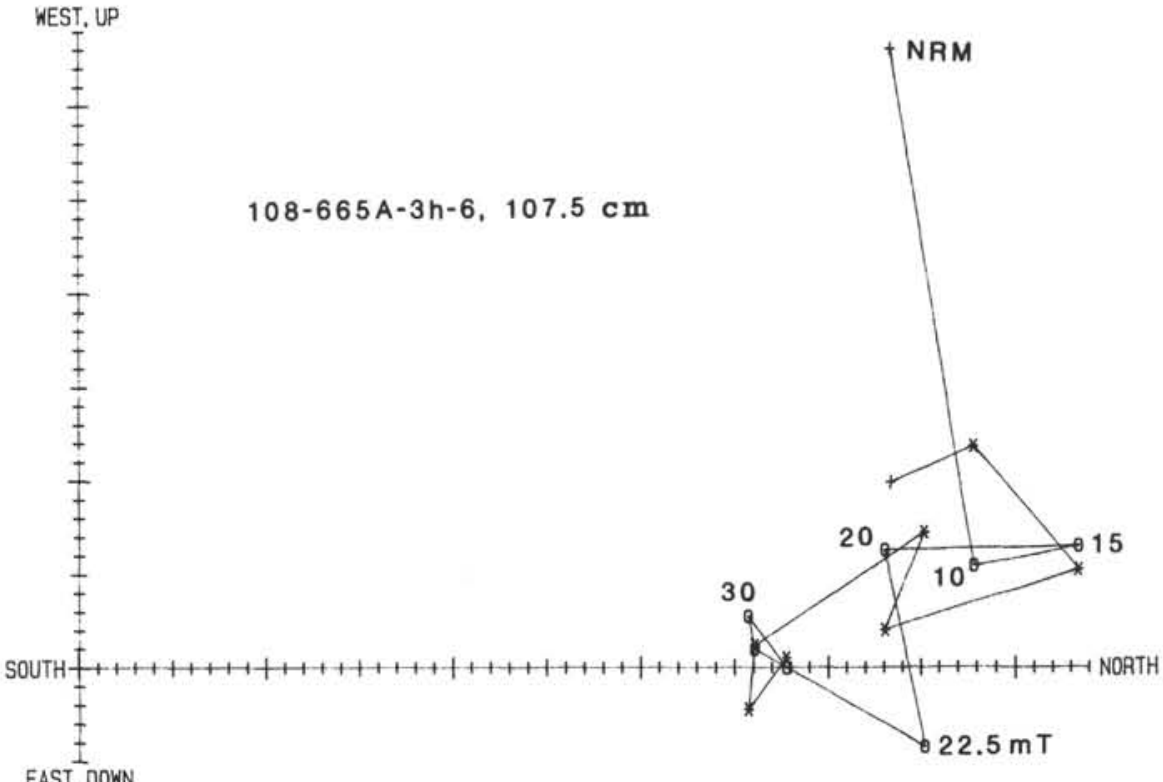

EAST, DOWN

Figure 3. Vector end-point diagrams showing the range of demagnetization behavior of sediments from Hole 665A. A. Thermal demagnetization of a normal sample from within the Jaramillo Subchron which exhibits nearly univectorial behavior and maximum unblocking temperatures of less than $600^{\circ} \mathrm{C}$. B. Alternating field demagnetization of a reversed sample from below the transition which has a small low-stability component removed by $20 \mathrm{mT}$, followed by linear decay to the origin at higher fields. C. Type A transitional sample that yields a reasonably well-defined characteristic magnetization although directions at $>25 \mathrm{mT}$ are compromised by ARM introduced during demagnetization. D. Type B transitional sample with low intensity which displays scattered directions, probably reflecting a significant ARM contribution even at low fields. Circles are projections onto the vertical plane; asterisks onto the horizontal plane. Tick marks are plotted every $10^{-9} \mathrm{Am}^{2}(\mathrm{~A}), 10^{-10} \mathrm{Am} \mathrm{m}^{2}(\mathrm{~B})$, and $10^{-11} \mathrm{Am} \mathrm{m}^{2}(\mathrm{C}$ and $\mathrm{D})$. 

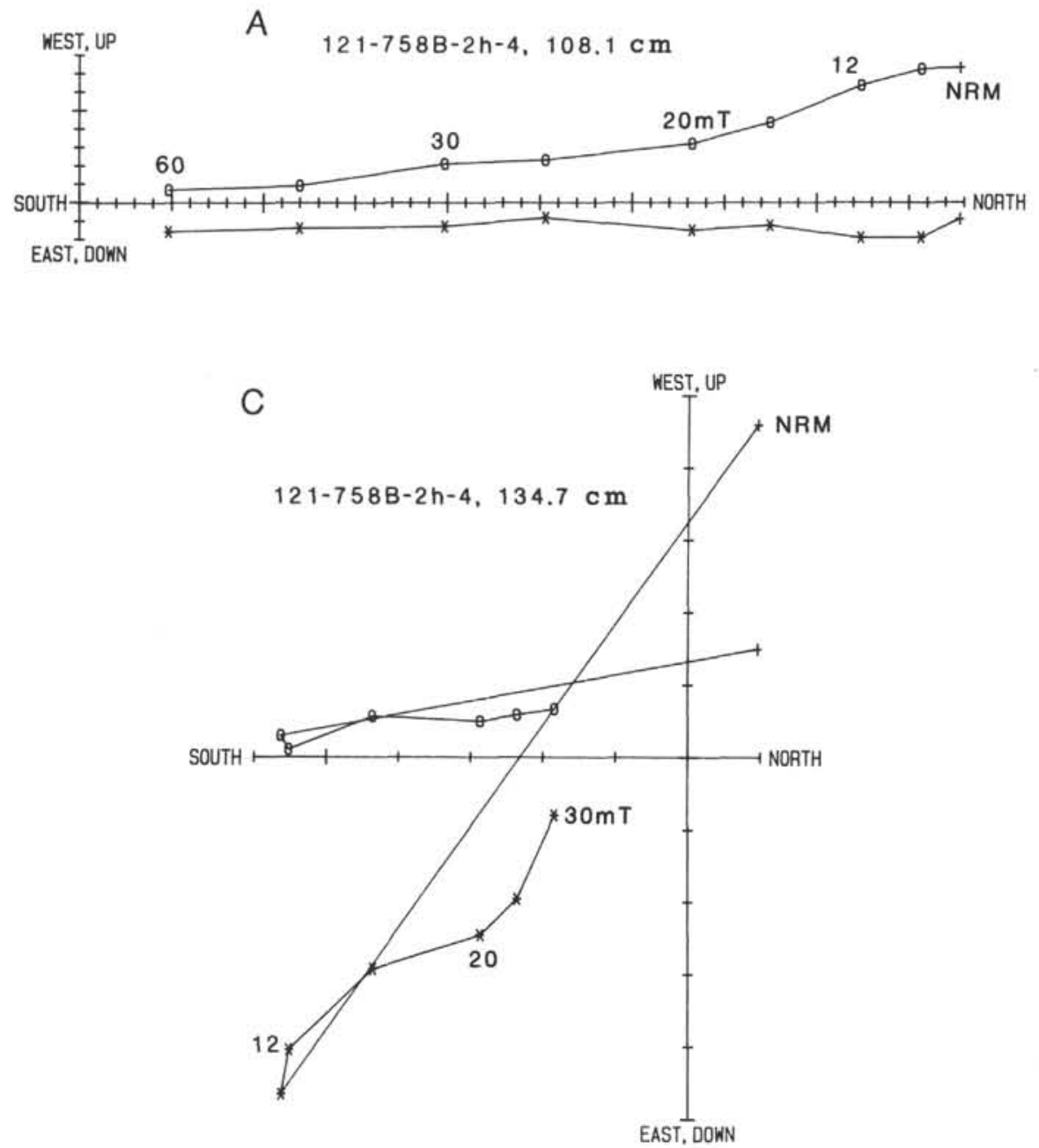

B

$121-758 \mathrm{~B}-2 \mathrm{~h}-4,148.6 \mathrm{~cm}$

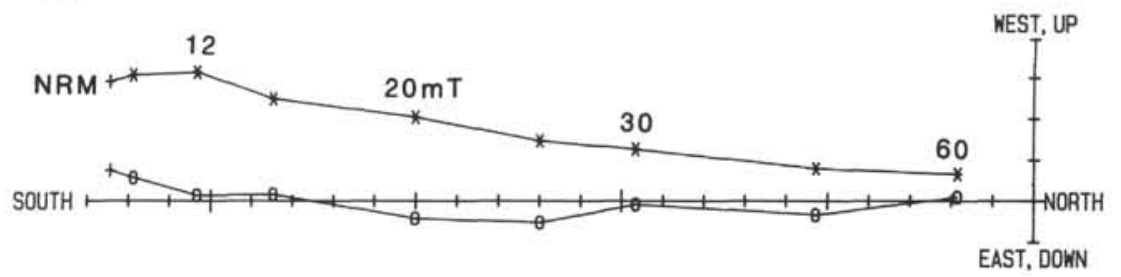

$121-758 \mathrm{~B}-2 \mathrm{~h}-4,133.3 \mathrm{~cm}$

D

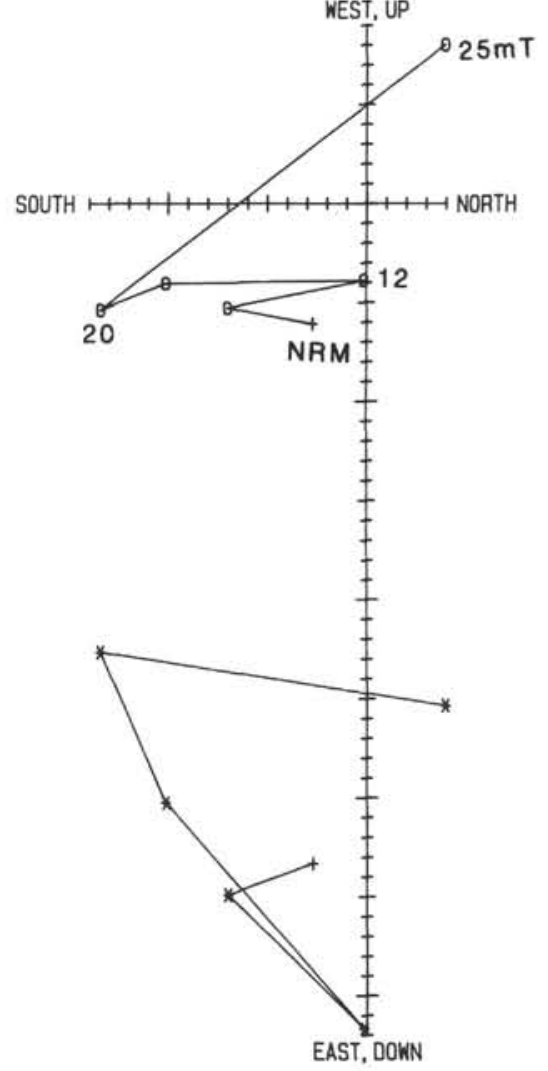

Figure 4. Vector end-point diagrams showing the range of AF demagnetization behavior in sediments from Hole 758B. Normal (A) and reversed (B) samples from outside the transitional interval are characterized by small low-stability components and linear decay to the origin at fields $>20 \mathrm{mT}$. Transitional samples include both type A (C) samples that give well-defined principal components and samples with more ambiguous (type B) demagnetization behavior (D). Symbols as in Figure 3. Tick marks are plotted every $10^{-10} \mathrm{Am}^{2}(\mathrm{~A}-\mathrm{C})$ and $10^{-11} \mathrm{Am}^{2}(\mathrm{D})$. 
A

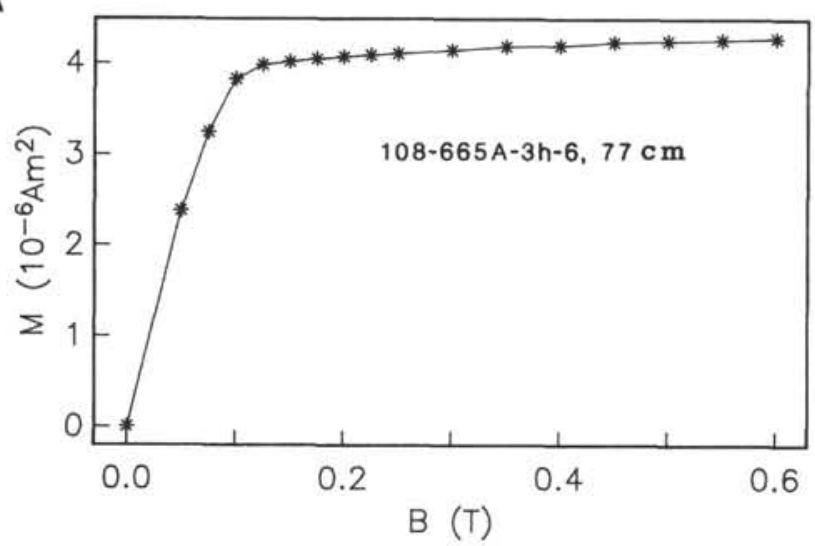

B

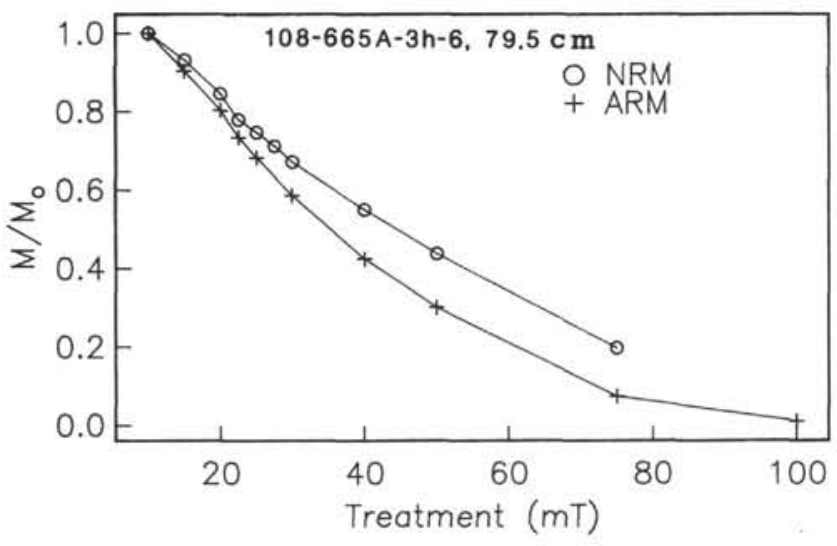

C

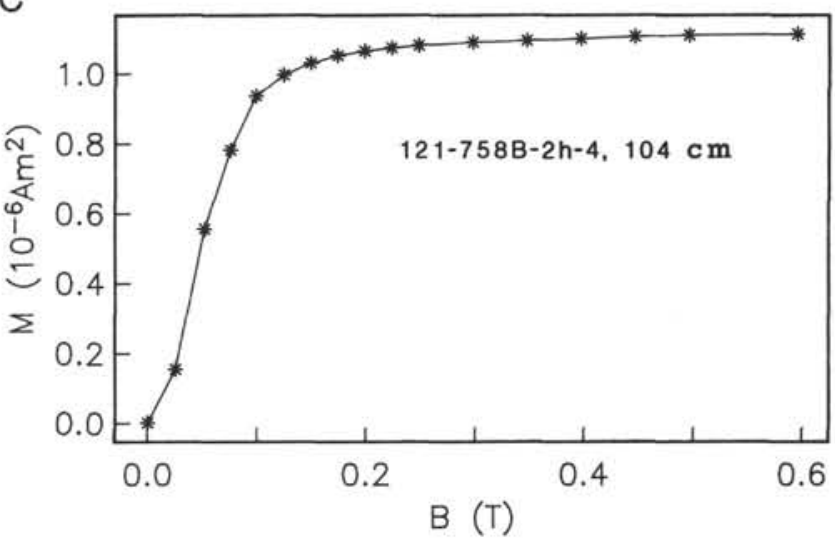

D

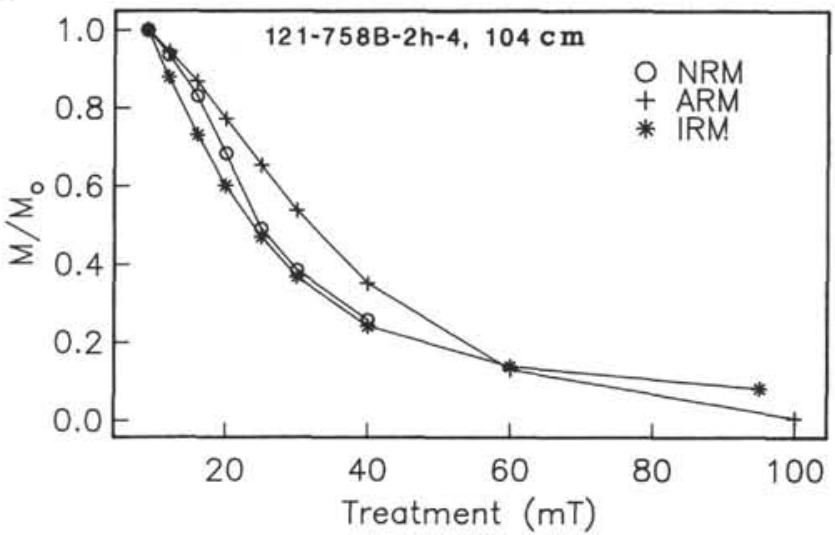

Figure 5. IRM acquisition and comparison of ARM, IRM, and NRM stability to AF demagnetization for samples from Holes 665A and 758B. Samples from both holes $(\mathbf{A}$ and $\mathbf{C}$ ) achieve saturation IRM in fields of $<0.3 \mathrm{~T}$, indicating that high-coercivity phases do not contribute significantly to the remanence. Demagnetization behaviors of ARM and NRM are not systematically similar, suggesting that ARM is not an appropriate parameter for normalizing intensity variations (B and D).

ity (Fig. 7) suggests that the grain size varies from approximately 0.1 to $15 \mu \mathrm{m}$ (King et al., 1983). Intervals in Figure 6 with $\mathrm{ARM} / \chi$ ratios greater than about 200 are characterized by grain sizes smaller than the 1-15- $\mu \mathrm{m}$ range suitable for paleointensity determinations (King et al., 1983). Excluding these intervals (designated by circles in Fig. 6E), the normalized NRM intensity record exhibits a broad low in the vicinity of the transition which probably represents a reduction in the geomagnetic field intensity. The large fluctuations (factor of 3-4) in the normalized intensity record above the transition, however, are most likely related to lithologic and grain-size variations. These results indicate that these sediments cannot be considered as a reliable record of paleointensity.

\section{Directional Data}

In Figure 8, we plot the directional data from Holes $665 \mathrm{~A}$ and 758B. Because our data are from azimuthally unoriented cores, we adjusted the average normal magnetization, calculated from the combined type A and B data at the top of each section, to zero. Despite the lack of paleointensity information, several observations indicate that the sediments from Holes $665 \mathrm{~A}$ and $758 \mathrm{~B}$ provide a reasonable record of directional changes in the geomagnetic field. First, the Pleistocene sediments from Hole $665 \mathrm{~A}$ and the Pliocene-Pleistocene sediments from Hole 758B both preserve an excellent magnetostratigraphic record in which declination reversals are evident without demagnetization or after treatment at low ( 5 to $9 \mathrm{mT}$ ) alternating fields. Although some weakly magnetic transitional samples exhibit scattered directions at high peak fields, the small secondary components observed outside the transitional interval suggest that the directions of transitional samples after 10 (Site 665) or $9 \mathrm{mT}$ (Site 758) may approximate the field direction.

Second, serially correlated inclination variations outside the transition are evident in the NRM data (Figs. 1 and 2) from both cores. The persistence of these features after stepwise demagnetization (e.g., $114 \mathrm{~cm}$ depth in Section 108-665A-3H-6; $113 \mathrm{~cm}$ in Section 121-758B-2H-4) suggests that they may represent a smoothed record of secular variation. The depth of postdepositional remanence acquisition in marine sediments has been estimated at $>10 \mathrm{~cm}$ (e.g., Hyodo, 1984; DeMenocal et al., 1990); however, the inclination variations in the Hole $665 \mathrm{~A}$ and $758 \mathrm{~B}$ sediments suggest that relatively short wavelength features $(<3-5$ $\mathrm{cm}$ ) are preserved during this filtering.

Third, the nontransitional directions are in general agreement with those observed in globally distributed deep-sea sediment cores (Schneider and Kent, 1988). The adjusted average directions for Hole $665 \mathrm{~A}$ are $\mathrm{D}=0^{\circ}, \mathrm{I}=2.5^{\circ}\left(n=46, \alpha 95=1.1^{\circ}\right)$ for the normal data and $\mathrm{D}=184.9, \mathrm{I}=13.7\left(n=20, \alpha_{95}=2.2^{\circ}\right)$ for the reversed data. The positive inclination of the reversed samples may in part be due to an incompletely removed low-stability component, as complete demagnetization of reversed samples below the transition results in a somewhat shallower positive inclination $\left(7.4^{\circ}\right)$. The mean adjusted directions for Hole $758 \mathrm{~B}$ are $\mathrm{D}=0^{\circ}, \mathrm{I}=1.6^{\circ}\left(n=51, \alpha_{95}=1.4^{\circ}\right)$ for the normal and $\mathrm{D}=$ $187.1, \mathrm{I}=-3.9^{\circ}\left(n=13, \alpha_{95}=1.6^{\circ}\right)$ for the reversed data. The Brunhes and Gauss (normal) data and the Matuyama and Gilbert 
E

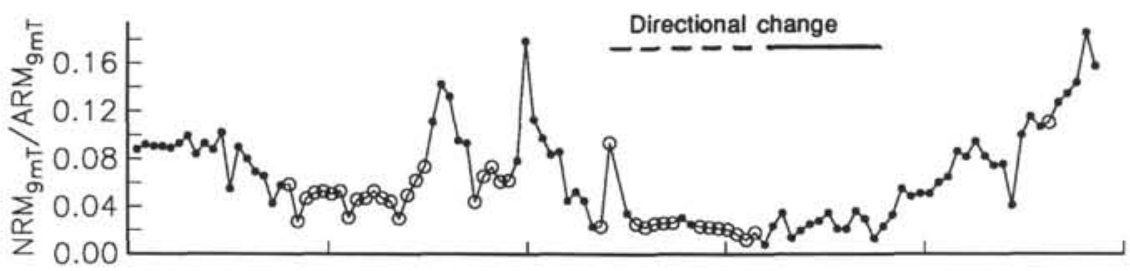

D

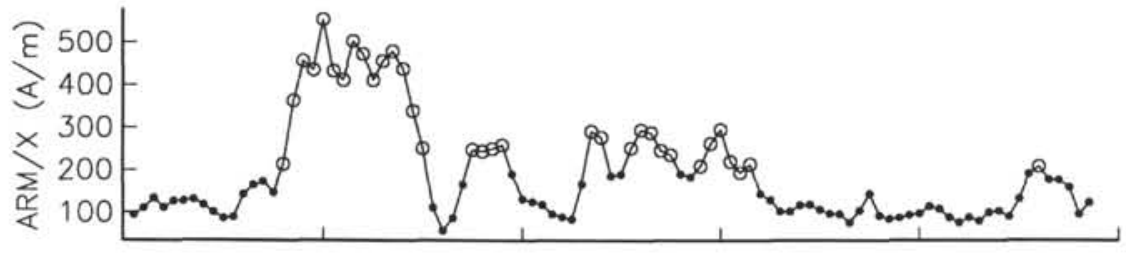

C

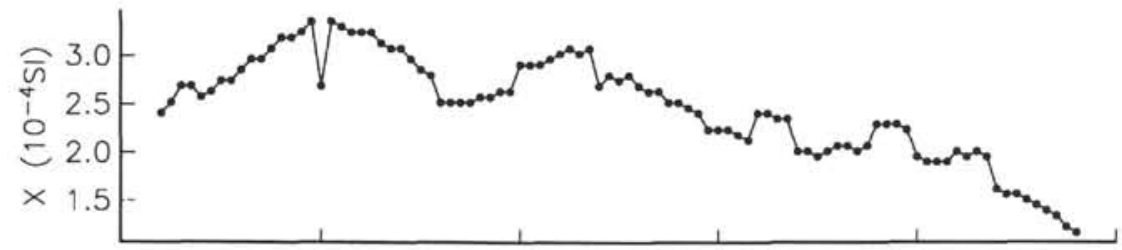

B

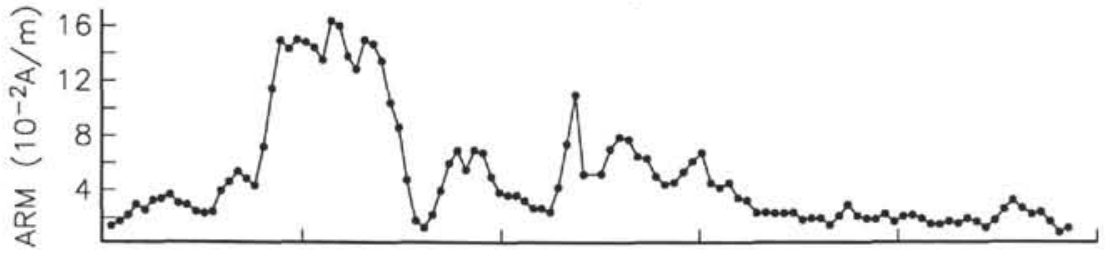

A

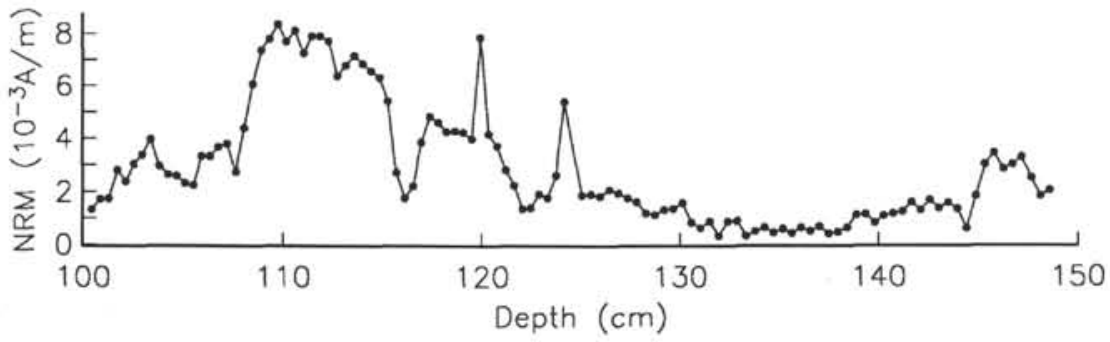

Figure 6. Variations in NRM intensity (A), ARM intensity (B), susceptibility (C), ARM/ $\chi(\mathbf{D})$, and normalized remanence (E) with depth in Section 121-758B-2H-4. The ARM and NRM profiles are quite similar. Susceptibility variations, although determined from the $U$ channel, are relatively minor and thus imply large grain-size changes as determined by the $\mathrm{ARM} / \chi$ ratio. The strong negative correlation between normalized NRM intensity and ARM, particularly in the upper part of the section, suggests that these sediments are not suitable for paleointensity determination. Open symbols designate samples with an $A R M / \chi>200$, suggesting a grain size not suitable for paleointensity determination.

(reversed) data of Schneider and Kent (1988) were combined into normal and reversed polarity groups (Fig. 9) that are quite similar to the Brunhes and Matuyama data sets alone. We plotted paleolatitude vs. observed inclination for each group along with the inclination expected from a geocentric axial dipole (GAD). The mean inclination data from the Jaramillo from our two records (triangle, Hole 665A; square, Hole 758B) are shown with the normal polarity group, and the pre-Jaramillo data are plotted with the reversed polarity group. The data from Site 758 were corrected for the small (about $50 \mathrm{~km}$ ) northward motion of Ninetyeast Ridge in the past million years (Peirce, Weissel, et al., 1989). Our data are entirely consistent with the global data set. Moreover, this consistency at the subchron level supports the contention (Schneider and Kent, 1988) that the observed difference between normal and reversed inclinations is due in part to a polarity-de- pendent nondipole contribution rather than temporal changes in the time-averaged field.

\section{Details of the Transitional Field}

Although the weak magnetization and complex demagnetization behavior of some transitional samples suggest that the record of the transitional field is less than perfect, both Sites 665 and 758 have type $\mathrm{A}$ intermediate directions that approximate the transitional field direction. It is readily apparent from the directional variations (Fig. 8) that the two equatorial sites give very different transitional paths. The reversed to normal record from Site 665 displays a counterclockwise rotation of declination whereas the transition record at Site 758 is characterized by a more gradual clockwise shift in declination. Although a positive inclination peak is suggested by the whole-core measurements from both 


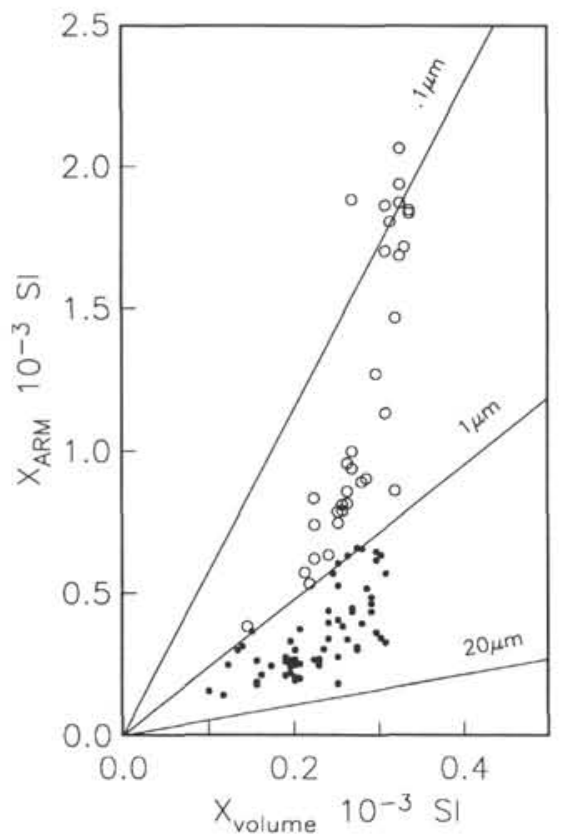

Figure 7. Susceptibility vs. $\chi_{\text {ARM }}$ (defined as the ratio of the ARM intensity to the bias field, where both are expressed in $\mathrm{A} / \mathrm{m}$ ) for samples from Hole 758B. Grain sizes between approximately 1 and $15 \mu \mathrm{m}$ (solid symbols) are suitable for paleointensity determination (King et al., 1983). Open symbols designate grain sizes smaller than $1 \mu \mathrm{m}$. cores (Figs. 1 and 2), the inclination values from Hole 758B show increased scatter but no coherent increase in magnitude. The Hole $665 \mathrm{~A}$ record exhibits a poorly defined inclination peak early in the transition, followed by scattered negative inclinations that gradually approach the normal value.

A more useful way to examine the details of the transitional path is to project the directional data relative to the direction expected from a GAD at the site ( $D^{\prime} I^{\prime}$ space of Hoffman, 1984). In this projection, the center of the equal-area plot is the GAD direction at the site and near- and far-sided transitional paths correspond to directions in the quadrants centered on $180^{\circ}$ and $0^{\circ}$, respectively. We define transitional samples as those with directions more than $30^{\circ}$ away from the expected GAD direction. Although the transitional data defined by a single demagnetization step are also included in Figure 10, the exclusion of these data reduces the number of transitional points but otherwise does not significantly alter the transitional path.

The transitional record from Hole $665 \mathrm{~A}$ cannot be readily classified as far-sided or near-sided (Fig. 10A). The reversed directions immediately preceding the transition exhibit the anomalous positive inclinations seen in virtually all marine sediment cores (Schneider and Kent, 1988) and thus are offset from the reversed GAD direction. The transitional record, as defined in the preceding, extends from 111.5 to $100.0 \mathrm{~cm}$. The reversal path initiates with a clockwise loop centered on an azimuth of $225^{\circ}$, which ends with normal directions near the GAD value. This is followed by a smaller counterclockwise loop that includes several marginally transitional samples in the far-sided quadrant and then progresses toward the normal GAD direction. The lower Jaramillo transition spans approximately $6 \mathrm{~cm}$ excluding the looping in the
A

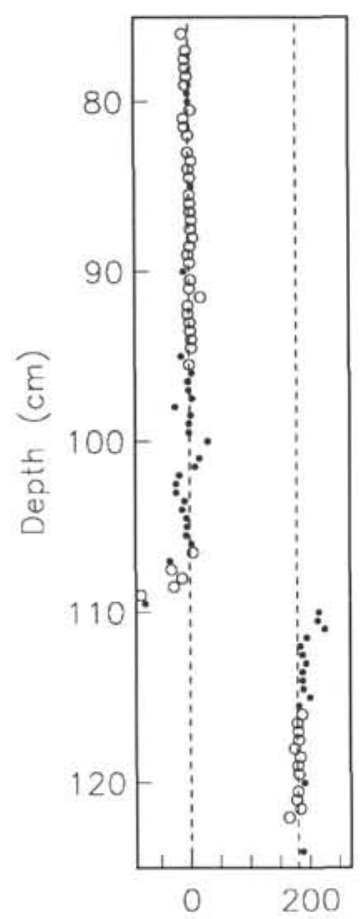

Declination

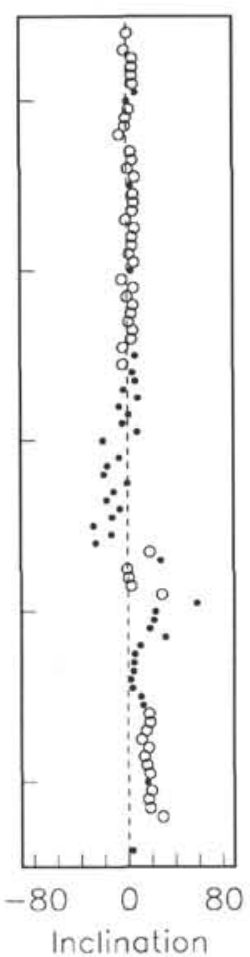

B

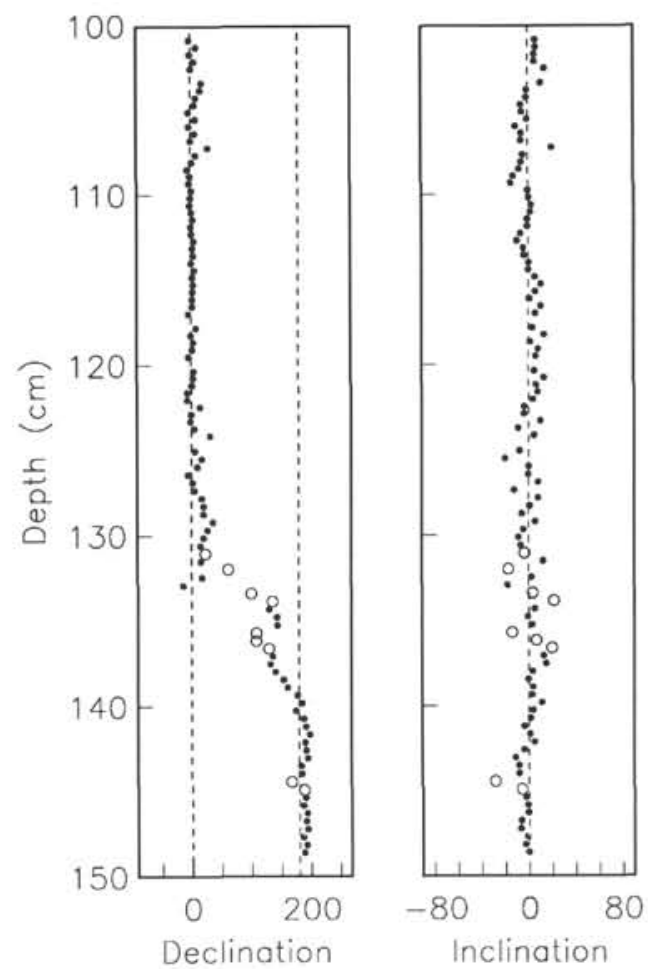

Figure 8. Discrete sample declination and inclination variation across the lower Jaramillo transition from Holes 665A (A) and 758B (B). The declination for both records was adjusted such that the mean normal direction is zero. Open symbols designate type A sample directions (in degrees); solid symbols designate type B. Depth is relative to the top of Sections 108-665A-3H-6 (A) and 121-758B-2H-4 (B). 


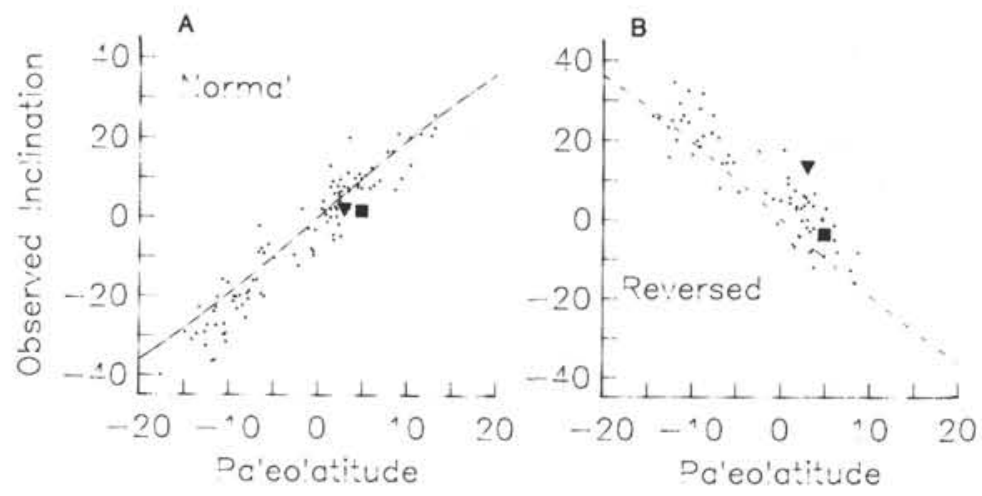

Figure 9. Observed inclination variation with paleolatitude for sediments from Holes $665 \mathrm{~A}$ and 758B and other equatorial deep-sea sediment cores. Both the normal (Brunhes and Gauss, A) and reversed (Matuyama and Gilbert, B) inclinations from the globally distributed equatorial data (dots; data from Schneider and Kent, 1988) deviate from the inclination expected from a geocentric axial dipole (line). The mean normal and reversed inclinations from Holes $665 \mathrm{~A}$ (triangles) and $758 \mathrm{~B}$ (squares) are consistent with the global data set.

latter part of the record. This suggests a duration of $2500 \mathrm{yr}$, whereas including the looping late in the record results in an estimate twice as long.

The record of the lower Jaramillo transition at Hole $758 \mathrm{~B}$ is also neither far-sided nor near-sided (Fig. 10B). The reversed directions preceding the reversal are offset from the GAD direction, reflecting the anomalously shallow inclinations discussed previously. The transitional directions initially progress eastward and define a counterclockwise loop that is neither far-sided nor near-sided. Whether or not the transitional directions defined by a single demagnetization step are included, the transitional path crosses the equator in the east-sided quadrant and then proceeds through numerous marginally far-sided directions to the expected GAD direction. As in the Hole 665A record, the duration of the transition depends on whether the looping behavior at the end of the reversal is included. A sedimentation rate of $2.5 \mathrm{~cm} / 1000 \mathrm{yr}$ suggests that the record from the first transitional sample (87; $138.0 \mathrm{~cm}$ ) to the initial recovery of normal directions (sample 75; $132.4 \mathrm{~cm}$ ) represents approximately $2400 \mathrm{yr}$. Including all samples through the final transitional direction (sample $58 ; 124.2 \mathrm{~cm}$ ) results in a significantly longer (5500 yr) duration. The shorter duration estimates for the lower Jaramillo transition records presented here are consistent with the latitudinal dependence of the reversal duration proposed by Clement and Kent (1984b). The much greater duration implied by including all transitional directions and the more recent records of the Matuyama/Brunhes reversal (Valet et al., 1989), however, do not support any latitudinal dependence.

\section{DISCUSSION}

Valet et al. (1988b) suggested three criteria for assessing the reliability of transition records: (1) complete stepwise demagnetization of all transitional samples, (2) investigation of the magnetic mineralogy, and (3) a minimum of four intermediate directions distributed in both hemispheres. In addition, it is essential that the identification of the reversal boundary is unambiguous. Although the rigorous application of such selection criteria is a matter of discussion, we have used these criteria as a general guideline for evaluating the reliability of the available lower Jaramillo records.

Petrova and Rassanova (1985) compiled a number of transition records, some eight of which were attributed to the lower Jaramillo. These are listed in Table 1 together with the more recent records published by Clement and Kent (1984a; 1986), Theyer et al. (1985), and Chauvin et al. (1990) and the two equatorial records presented here. The age control for many of these records is poor and the identification of the reversal boundary is ambiguous. On these grounds we exclude the Cerveny and Sedlec records. Of the three Pacific Ocean records (K7501, K7502, and K781030), only one has intermediate directions (K781030). The published transitional path from this core (Theyer et al., 1985; Herrero-Bervera and Theyer, 1986) is based on a moving average of highly scattered data and we consider this record to be less reliable. The most recently published transitional path for the lower Jaramillo is a volcanic record from Tahiti (Chauvin et al., 1990). Although the age control for this record is sufficient for positive identification, only a single (marginally) transitional direction was recorded.

There are three records from Turkmenia which trace similar transitional paths, and we have selected one of these (Adzhidere) for comparison with our records. The record from RC 14-14 of Opdyke et al. (1973) was superseded by the study of Clement and Kent (1984a). Complete demagnetization of 20 pilot specimens suggested a univectorial magnetization and the magnetic mineralogy was determined to be magnetite. Although transitional specimens were subjected to blanket demagnetization at $10 \mathrm{mT}$, this record remains perhaps the best ever obtained for the lower Jaramillo. Similarly, the lower Jaramillo record from Hole 609B (Clement and Kent, 1986) has been retained although the magnetic mineralogy was not determined. We therefore have only three records, in addition to our two equatorial records, of the lower Jaramillo which approach the suggested minimal criteria for reliability. These records are plotted with respect to common site longitude in Figure 11.

The most striking feature of the records shown in Figure 11 is that none is constrained to the site longitude or its antipode, as required by axisymmetric models for the transitional field. The records from Holes $609 \mathrm{~B}$ and $665 \mathrm{~A}$ are both from sites along the $340^{\circ}$ meridian. These two VGP paths initiate along a similar longitude relative to the site $\left(60^{\circ}-80^{\circ}\right.$ east of the site); however, there are few other similarities between the two records. Similarly, the Adzhidere, Hole 758B, and RC 14-14 records are all from sites in a longitudinal band from $55^{\circ}-90^{\circ} \mathrm{E}$. The record from RC 14-14 is much more detailed than the corresponding path from equatorial Hole $758 \mathrm{~B}$. The latter path is closely confined along a meridian $90^{\circ}$ east of the site. Although both reversal records initiate approximately $90^{\circ}$ east of the site, large portions of the RC 14-14 transitional path can be classified as far-sided. Portions of the Northern Hemisphere record from Adzhidere can likewise 
A

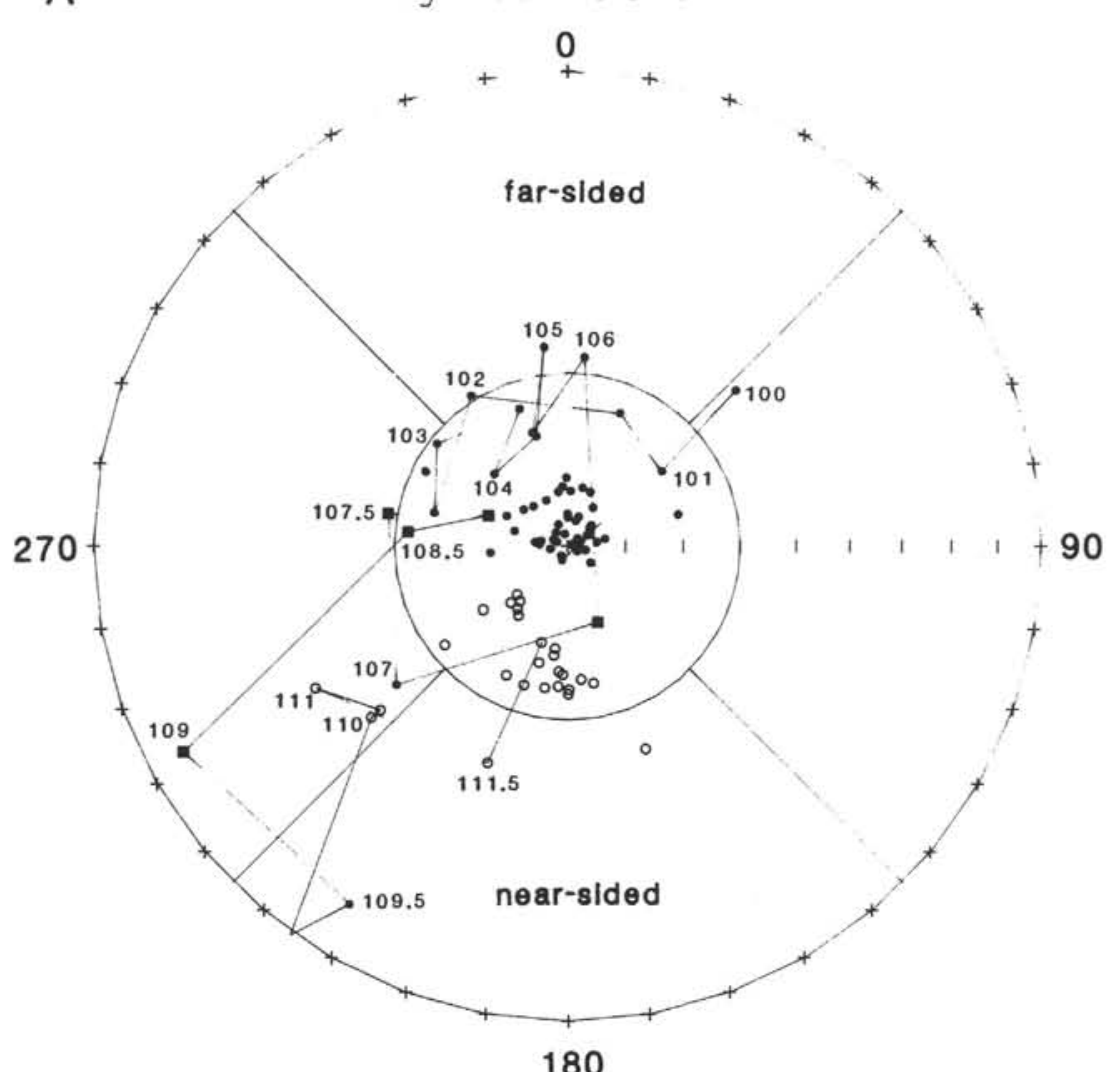

B

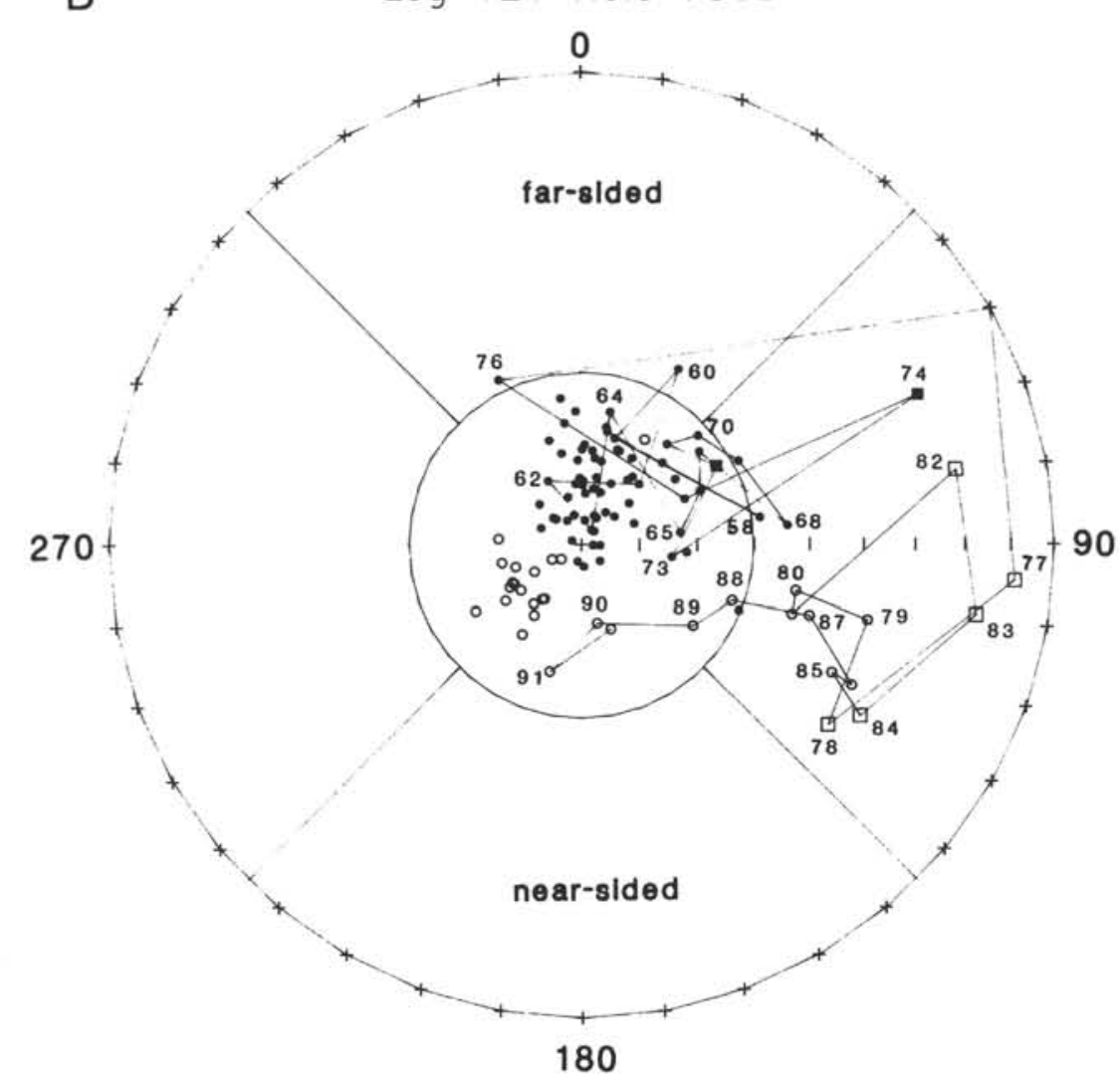

Figure 10. Directional variations of the lower Jaramillo transitions relative to the expected dipole direction. Solid circles represent directions in the lower hemisphere; open circles in the upper hemisphere. Transitional samples are defined as those with directions $>30^{\circ}$ away from the expected dipole direction (center of plot). Type B transitional directions are indicated by a solid square (lower hemisphere) or an open square (upper hemisphere). Sample depths are indicated for Hole 665A (A), and sample numbers are given for Hole 758B (B, see Appendix B). Neither transitional path is consistent with a field morphology dominated by zonal terms. 

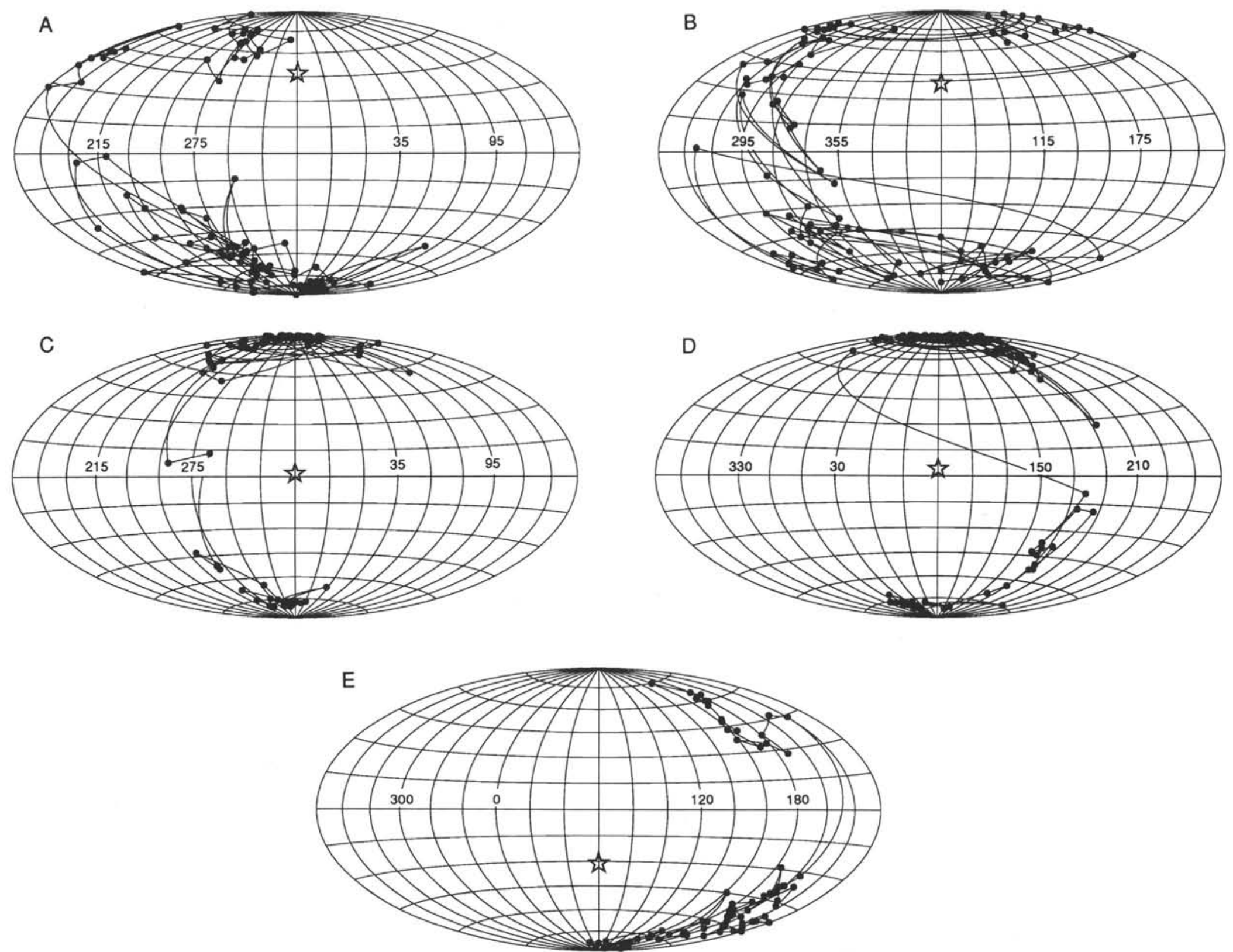

Figure 11. Virtual geomagnetic pole (VGP) paths for lower Jaramillo transitional records that meet minimal reliability criteria. All records are plotted with respect to common site longitude. The Hole 609B (A) and Hole 665A (C) records constitute a partial latitudinal transect along 340 ${ }^{\circ} \mathrm{E}$. The Adzhidere (B), Hole 758B (D), and RC 14-14 (E) records are all located within a longitudinal band $\left(55^{\circ}-90^{\circ} \mathrm{E}\right)$. Although portions of the records in Figures $11 \mathrm{~A}, 11 \mathrm{~B}$, and $11 \mathrm{E}$ can be considered far-sided, there is no compelling evidence for axisymmetry during the lower Jaramillo reversal. The labeled meridians are in east longitude. 
be classified as far-sided; however, the early and intermediate portions of this record are distinctly different than those from Hole 758B and RC 14-14.

Comparison of the inclination and intensity variations during the Olduvai termination and Jaramillo onset recorded at RC 14-14 led Clement and Kent (1985) to suggest that standing nondipole field components dominated these successive transition records. In particular, the Jaramillo record exhibits $-90^{\circ}$ inclinations late in the reversal and the Olduvai record has similarly steep negative inclinations early in the reversal record. Although the similarities between the two successive records provide support for the importance of a standing field at RC 14-14, the lack of steep negative inclinations in the Hole 758B record suggests that the morphology of any such standing field must be complex.

The processes of remanence acquisition in sediments may significantly smooth the record of the transitional field (e.g., Hoffman and Slade, 1986). Valet et al. (1989) have shown that such postdepositional smoothing should preserve any axisymmetric features of the record, especially at equatorial sites. In a recent study of the effects of filtering on records of geomagnetic reversals, however, Rochette (1990) demonstrated that time-averaging between nonantipodal directions can lead to records that mimic those predicted by low-order zonal harmonic models. In particular, a declination discrepancy between stable normal and reversed polarity directions may lead to smoothed transitional records confined along a meridian $90^{\circ}$ from the site (Rochette, 1990). Thus, the possibility that the nonzonal nature of the equatorial records presented here arises from postdepositional remanence acquisition processes cannot be dismissed.

Despite the observation that large parts of the RC 14-14, Adzhidere, and Hole 609B records can be categorized as farsided, the transitional paths shown in Figure 6 indicate that the demands of axisymmetry clearly are not met. Such nonaxisymmetric behavior has been noted previously (e.g., Valet et al., 1989). In order to model such a complex, nonaxisymmetric field morphology to even third order requires some 15 terms. There are only five records of the lower Jaramillo transition which meet minimum reliability standards. Thus, characterization of the harmonic content of the field during the onset of the Jaramillo Subchron is, at best, premature.

\section{CONCLUSIONS}

Two records of the lower Jaramillo transition have been obtained from the equatorial Atlantic (Site $665 ; 2.95^{\circ} \mathrm{N}, 340.33^{\circ} \mathrm{E}$ ) and Indian (Site $758 ; 5.38^{\circ} \mathrm{N}, 90.35^{\circ} \mathrm{E}$ ) oceans. Grain-size variations, as determined by variations in ARM intensity vs. susceptibility, prohibit the determination of relative paleointensity in these sediments. Despite the low intensities and ambiguous demagnetization behavior in some transitional samples, a small number of intermediate directions in both records defines transitional paths that are neither near-sided nor far-sided. Together with published records that approach minimum reliability standards, the two equatorial records presented here suggest that the lower Jaramillo transitional field morphology was significantly nonaxisymmetric. The mean normal and reversed inclinations outside the transition in both cores deviate from the inclination expected from a geocentric axial dipole but are consistent with the observed inclination variations from a globally distributed set of deep-sea cores (Schneider and Kent, 1988). This consistency provides further support for a polarity-dependent nondipole contribution to the time-averaged field.

\section{ACKNOWLEDGMENTS}

We thank B. Clement and D. Kent for providing data and C. Constable and R. L. Parker for helpful discussions. We thank J. Hillhouse, K. Hoffman, and J.-P. Valet for reviews that signifi- cantly improved the text. We are especially grateful to J.-P. Valet, who participated in Leg 108 and initiated the Leg 108 study. T. Toma aided with sample measurements. This research was partially supported by NSF Grants EAR 85-0919 and OCE90-00182 and USSAC grants to J. Gee and to L. Tauxe. E. Barg was partially supported by a fellowship from the Korean government as well as by NSF. Funds for the Scripps Paleomagnetic Lab were kindly provided by the Keck Foundation.

\section{REFERENCES}

Berggren, W. A., Kent, D. V., Flynn, J. J., and Van Couvering, J. A., 1985. Cenozoic geochronology. Geol. Soc. Am. Bull., 96:1407-1418.

Bogue, S. W., and Hoffman, K. A., 1987. Morphology of geomagnetic reversal. Rev. Geophys., 25:910-916.

Bucha, V., 1970. Geomagnetic reversals in Quaternary revealed from a palaeomagnetic investigation of sedimentary rocks. J. Geomagn. Geoelectr., 22:253-371.

1973. The continuous pattern of variations of the geomagnetic field in the Quaternary and their causes. Stud. Geophis. Geodaet., 17:218-231.

Chauvin, A., Roperch, P., and Duncan, R. A., 1990. Records of geomagnetic reversals from volcanic islands of French Polynesia. 2. Paleomagnetic study of a flow sequence $(1.2-0.6 \mathrm{Ma})$ from the island of Tahiti and discussion of reversal models. J. Geophys. Res., 2752.

Clement, B. M., and Kent, D. V., 1984a. A detailed record of the lower Jaramillo polarity transition from a Southern Hemisphere, deep-sea sediment core. J. Geophys. Res., 89:1049-1058.

1984b. Latitudinal dependency of geomagnetic polarity transition duration. Nature, 310:488-491.

1985. A comparison of two sequential geomagnetic polarity transitions (upper Olduvai and lower Jaramillo) from the Southern Hemisphere. Phys. Earth Planet. Inter., 39:301-313.

1986. Geomagnetic polarity transition records from five hydraulic piston core sites in the North Atlantic. In Ruddiman, W. F., Kidd, R. B., Thomas, E., et al., Init. Repts. DSDP, 94: Washington (U.S. Govt. Printing Office), 831-852.

Constable, C. G., 1990. A simple statistical model for geomagnetic reversals. J. Geophys. Res., 95:4587-4596.

Constable, C. G., and Parker, R. L., 1988. Statistics of the geomagnetic secular variation for the past 5 m.y. J. Geophys. Res., 93:1156911582.

Cox, A., Doell, R. R., and Dalrymple, G. B., 1963. Geomagnetic polarity epoch and Pleistocene geochronometry. Nature, 198:1049-1051.

1964. Reversals of the Earth's magnetic field. Science, 144:1537-1543.

DeMenocal, P. B., Ruddiman, W. F., and Kent, D. V., 1990. Depth of post-depositional remanence acquisition in deep-sea sediments: a case study of the Brunhes-Matuyama reversal and oxygen isotopic stage 19.1. Earth Planet. Sci. Lett., 99:1-13.

Gurarii, G. Z., 1981. The Matuyama-Jaramillo geomagnetic inversion in western Turkmenia, Izvestiya. Earth Phys., 17:212-218.

Hammond, S. R., Seyb, S. M., and Theyer, F., 1979. Geomagnetic polarity transitions in two oriented sediment cores from the northwest Pacific. Earth Planet. Sci. Lett., 44:167-175.

Herrero-Bervera, E., and Theyer, F., 1986. Non-axisymmetric behaviour of Olduvai and Jaramillo polarity transitions recorded in north-central Pacific deep-sea sediments. Nature, 322:159-162.

Hillhouse, J., and Cox, A., 1976. Brunhes-Matuyama polarity transition. Earth Planet. Sci. Lett., 29:51-64.

Hoffman, K. A., 1977. Polarity transition records and the geomagnetic dynamo. Science, 196:1329-1332.

1979. Behavior of the geodynamo during reversal: a phenomenological model. Earth Planet. Sci. Lett., 44:7-17.

1982. The testing of geomagnetic reversal models: recent developments. Philos. Trans. R. Soc. London A, 306:147-159.

1984. A method for the display and analysis of transitional paleomagnetic data. J. Geophys. Res., 89:6285-6292.

Hoffman, K. A., and Fuller, M., 1978. Transitional field configurations and geomagnetic reversal. Nature, 273:715-718.

Hoffman, K. A., and Slade, S. B., 1986. Polarity transition records and the acquisition of remanence: a cautionary note. Geophys. Res. Lett., 13:483-486. 
Hyodo, M., 1984. Possibility of reconstruction of the past geomagnetic field from homogeneous sediments. J. Geomagn. Geoelectr., 36:4562.

King, J. W., Banerjee, S. K., and Marvin, J., 1983. A new rock magnetic approach to selecting sediments for geomagnetic paleointensity studies: application to paleointensity for the last 4000 years. J. Geophys. Res., 88:5911-5921.

Kirschvink, J. L., 1980. The least-squares line and plane analysis of palaeomagnetic data. Geophys. J. R. Astron. Soc., 62:699-718.

Levi, S., and Banerjee, S. K., 1976. On the possibility of obtaining relative paleointensities from lake sediments. Earth Planet. Sci. Lett., 29:219-226.

Opdyke, N. D., Kent, D. V., and Lowrie, W., 1973. Details of magnetic polarity transitions recorded in a high deposition rate deep-sea core. Earth Planet. Sci. Lett., 20:315-324.

Peirce, J., Weissel, J., et al., 1989. Proc. ODP, Init. Repts., 121: College Station, TX (Ocean Drilling Program).

Petrova, G. N., and Rassanova, G. V., 1985. Geomagnetic Field Reversal (Catalog 1957-1982). Moscow (MTsD-B Material).

Rochette, P., 1990. Rationale of geomagnetic reversals versus remanence recording processes in rocks: a critical review. Earth Planet. Sci.Lett., 98:33-39.

Schneider, D. A., and Kent, D. V., 1988. The paleomagnetic field from equatorial deep-sea sediments: axial symmetry and polarity asymmetry. Science, 242:252-256.

Tauxe, L., LaBrecque, J. L., Dodson, R., and Fuller, M., 1983. "U" channels-a new technique for paleomagnetic analysis of hydraulic piston cores. Eos, Trans. Am. Geophys. Union, 64:219. (Abstract)
Tauxe, L., Valet, J.-P., and Bloemendal, J., 1989. Magnetostratigraphy of Leg 108 advanced hydraulic piston cores. In Ruddiman, W., Sarnthein, M., et al., Proc. ODP, Sci. Results, 108: College Station, TX (Ocean Drilling Program), 429-439.

Theyer, F., Herrero-Bervera, E., and Hsu, V., 1985. The zonal harmonic model of polarity transitions: a test using successive reversals. $J$. Geophys. Res., 90:1963-1982.

Valet, J.-P., Laj, C., and Langereis, C. G., 1988a. Sequential geomagnetic reversals recorded in upper Tortonian marine clays in western Crete (Greece). J. Geophys. Res., 93:1131-1152.

Valet, J.-P., Tauxe, L., and Clark, D. C., 1988. The Matuyama-Brunhes transition recorded from Lake Tecopa sediments. Earth Planet. Sci. Lett., 87:463-472.

Valet, J.-P., Tauxe, L., and Clement, B., 1989. Equatorial and mid-latitude records of the last geomagnetic reversal from the Atlantic Ocean. Earth Planet. Sci. Lett., 94:371-384.

Williams, I., and Fuller, M., 1981. Zonal harmonic models of reversal transition fields. J. Geophys. Res., 86:11657-11665.

Williams, I., Weeks, R., and Fuller, M., 1988. A model for transitional fields during geomagnetic reversals. Nature, 332:719-720.

Date of initial receipt: 30 April 1990

Date of acceptance: 11 December 1990

Ms 121B-152 
APPENDIX A

Directional Data for Hole 665A Lower Jaramillo Polarity Transition

\begin{tabular}{|c|c|c|c|c|c|c|c|c|c|}
\hline \multirow[b]{2}{*}{$\begin{array}{l}\operatorname{Depth}^{\mathrm{a}} \\
(\mathrm{cm})\end{array}$} & \multirow[b]{2}{*}{$\begin{array}{l}\text { Treatment } \\
\text { range }(\mathrm{mT})\end{array}$} & \multicolumn{4}{|c|}{ With origin } & \multicolumn{4}{|c|}{ Without origin } \\
\hline & & $n$ & $\begin{array}{c}\text { MAD }^{\mathrm{b}} \\
\text { (degrees) }\end{array}$ & $\begin{array}{c}\text { Declination } \\
\text { (degrees) }\end{array}$ & $\begin{array}{l}\text { Inclination } \\
\text { (degrees) }\end{array}$ & $n$ & $\begin{array}{c}\text { MAD } \\
\text { (degrees) }\end{array}$ & $\begin{array}{l}\text { Declination } \\
\text { (degrees) }\end{array}$ & $\begin{array}{c}\text { Inclination } \\
\text { (degrees) }\end{array}$ \\
\hline 76.0 & 10 & 1 & 0 & 349.7 & 0.6 & 1 & 0 & 349.7 & 0.6 \\
\hline 80.0 & $10.0-75.0+0$ & 10 & 5.7 & 0.0 & 0.3 & 9 & 7 & 2.1 & -0.3 \\
\hline 85.0 & $10.0-50.0+0$ & 9 & 7.8 & 3.8 & 2.7 & 8 & 7.8 & 8.3 & 5.3 \\
\hline 90.0 & $10.0-30.0+0$ & 8 & 7.7 & 351.0 & 3.2 & 7 & 9.7 & 1.0 & 2.2 \\
\hline$c^{c} 95.0$ & $20.0-30.0+0$ & 6 & 12.1 & 346.7 & 6.8 & 6 & 9.4 & 10.4 & 33.6 \\
\hline 95.5 & 10 & 1 & 0 & 0.5 & -3.6 & 1 & 0 & 0.5 & -3.6 \\
\hline 96.0 & $10.0-75.0+0$ & 10 & 9.5 & 3.4 & 3.9 & 9 & 11 & 5.8 & 4.1 \\
\hline 96.5 & $10.0-75.0+0$ & 10 & 9.2 & 357.0 & 6.3 & 9 & 10.8 & 356.0 & 6.8 \\
\hline 97.0 & $25.0-40.0+0$ & 4 & 3.8 & 358.4 & -3.5 & 3 & 6.3 & 354.3 & 2.3 \\
\hline 97.5 & $22.5-40.0+0$ & 5 & 11.2 & 4.0 & 8.6 & 4 & 19.1 & 355.0 & 1.2 \\
\hline 98.0 & $15.0-30.0+0$ & 7 & 11.8 & 335.6 & -7.2 & 6 & 18.2 & 7.4 & -1.7 \\
\hline 98.5 & $10.0-30.0+0$ & 7 & 9.8 & 1.9 & 0.8 & 6 & 18.4 & 3.3 & -2.6 \\
\hline 99.0 & $10.0-30.0+0$ & 7 & 15.1 & 359.1 & -4.4 & 6 & 25.7 & 11.8 & -7.4 \\
\hline 99.5 & $10.0-50.0+0$ & 9 & 9.9 & 359.0 & 8.2 & 8 & 12.8 & 2.7 & 9.9 \\
\hline 100.0 & $20.0-40.0+0$ & 6 & 11.1 & 30.5 & -20.8 & 5 & 23.7 & 16.2 & -32.8 \\
\hline${ }^{c} 101.0$ & $10.0-30.0+0$ & 7 & 8.6 & 16.3 & -7.1 & 7 & 7.7 & 26.7 & -11.1 \\
\hline 101.5 & $15.0-25.0+0$ & 5 & 5.1 & 9.4 & -17.0 & 4 & 24.1 & 8.7 & -14.7 \\
\hline 102.0 & $15.0-25.0+0$ & 4 & 8.3 & 343.0 & -20.0 & 3 & 11.4 & 21.0 & -30.9 \\
\hline$c_{102.5}$ & $22.5-30.0+O$ & 5 & 2.8 & 337.3 & -0.2 & 6 & 8 & 352.7 & 20.8 \\
\hline 103.0 & $10.0-25.0+0$ & 6 & 8.4 & 337.5 & -11.8 & 5 & 17.6 & 5.1 & 4.3 \\
\hline 103.5 & $10.0-20.0+0$ & 4 & 5.2 & 351.7 & -17.7 & 3 & 14.6 & 0.4 & -28.8 \\
\hline 104.0 & $10.0-30.0+0$ & 8 & 5.1 & 347.5 & -6.5 & 7 & 10 & 346.7 & -6.8 \\
\hline$c_{104.5}$ & $20.0-30.0+0$ & 6 & 10 & 354.7 & -13.0 & 9 & 7.5 & 9.7 & 2.6 \\
\hline 105.0 & $10.0-30.0+0$ & 8 & 6.4 & 355.7 & -28.7 & 7 & 6.3 & 350.0 & -35.5 \\
\hline 105.5 & $10.0-30.0+0$ & 8 & 12.9 & 354.0 & -13.6 & 7 & 27.2 & 337.1 & -21.7 \\
\hline 106.0 & $20.0-30.0+0$ & 6 & 12.6 & 3.2 & -26.9 & 5 & 15.4 & 35.1 & -52.1 \\
\hline 106.5 & 10 & 1 & 0 & 5.4 & 18.7 & 1 & 0 & 5.4 & 18.7 \\
\hline 107.0 & $15.0-30.0+0$ & 6 & 14 & 326.9 & 27.9 & 5 & 30.1 & 296.0 & 34.9 \\
\hline 107.5 & 10 & 1 & 0 & 329.1 & -0.3 & 1 & 0 & 329.1 & -0.3 \\
\hline 108.0 & 10 & 1 & 0 & 346.5 & 0.5 & 1 & 0 & 346.5 & 0.5 \\
\hline 108.5 & 10 & 1 & 0 & 332.5 & 2.8 & 1 & 0 & 332.5 & 2.8 \\
\hline 109.0 & 10 & 1 & 0 & 277.0 & 28.6 & 1 & 0 & 277.0 & 28.6 \\
\hline 109.5 & $15.0-22.5+0$ & 4 & 13.1 & 284.4 & 58.2 & 3 & 27.7 & 19.3 & 78.3 \\
\hline 110.0 & $10.0-22.5+0$ & 5 & 10.1 & 216.0 & 23.2 & 4 & 9.1 & 208.6 & 15.8 \\
\hline 110.5 & $10.0-25.0+0$ & 6 & 8.1 & 214.0 & 22.0 & 5 & 8.9 & 206.3 & 20.8 \\
\hline 111.0 & $10.0-25.0+0$ & 6 & 9.5 & 225.7 & 18.3 & 5 & 15.1 & 227.8 & 8.5 \\
\hline 111.5 & $10.0-25.0+0$ & 6 & 6.4 & 195.3 & 31.5 & 5 & 5.1 & 199.3 & 23.6 \\
\hline 112.0 & $0.0-30.0+0$ & 8 & 5.7 & 184.5 & 10.4 & 7 & 6.4 & 180.9 & 10.4 \\
\hline 112.5 & $10.0-22.5+0$ & 5 & 5.7 & 188.4 & 5.8 & 4 & 6.4 & 179.8 & -4.0 \\
\hline 113.0 & $10.0-25.0+0$ & 6 & 6.1 & 194.4 & 5.0 & 5 & 7.4 & 195.7 & -3.3 \\
\hline 113.5 & $15.0-25.0+0$ & 5 & 8.4 & 188.5 & 4.7 & 4 & 5.5 & 205.8 & 3.3 \\
\hline 114.0 & $10.0-30.0+0$ & 6 & 5.8 & 188.6 & 2.4 & 5 & 4.3 & 192.7 & -2.8 \\
\hline 114.5 & $10.0-30.0+0$ & 7 & 5.4 & 189.7 & 3.8 & 6 & 6.6 & 192.5 & 1.9 \\
\hline 115.0 & $15.0-30.0+0$ & 7 & 8.2 & 201.2 & 11.0 & 6 & 8.9 & 191.9 & 8.5 \\
\hline 115.5 & $10.0-30.0+0$ & 7 & 4.1 & 182.4 & 12.7 & 6 & 5.2 & 179.3 & 13.5 \\
\hline 116.0 & 10 & 1 & 0 & 187.7 & 17.8 & 1 & 0 & 187.7 & 17.8 \\
\hline 116.5 & 10 & 1 & 0 & 179.8 & 18.6 & 1 & 0 & 179.8 & 18.6 \\
\hline 117.0 & 10 & 1 & 0 & 181.6 & 15.5 & 1 & 0 & 181.6 & 15.5 \\
\hline 117.5 & 10 & 1 & 0 & 182.2 & 11.5 & 1 & 0 & 182.2 & 11.5 \\
\hline 118.0 & 10 & 1 & 0 & 175.4 & 17.5 & 1 & 0 & 175.4 & 17.5 \\
\hline 118.5 & 10 & 1 & 0 & 185.0 & 13.9 & 1 & 0 & 185.0 & 13.9 \\
\hline 119.0 & 10 & 1 & 0 & 180.9 & 16.0 & 1 & 0 & 180.9 & 16.0 \\
\hline 119.5 & 10 & 1 & 0 & 181.7 & 18.1 & 1 & 0 & 181.7 & 18.1 \\
\hline 120.0 & $10.0-30.0+0$ & 8 & 7.1 & 190.7 & 16.1 & 7 & 5.4 & 182.9 & 14.4 \\
\hline 120.5 & 10 & 1 & 0 & 179.9 & 19.4 & 1 & 0 & 179.9 & 19.4 \\
\hline 121.0 & 10 & 1 & 0 & 177.6 & 16.8 & 1 & 0 & 177.6 & 16.8 \\
\hline 121.5 & 10 & 1 & 0 & 184.1 & 18.3 & 1 & 0 & 184.1 & 18.3 \\
\hline 124.0 & $10.0-50.0+0$ & 9 & 6.2 & 188.1 & 3.5 & 8 & 7.1 & 186.5 & 5.4 \\
\hline
\end{tabular}

${ }^{\text {a }}$ Relative to the top of Section 108-665A-3H-6.

b $\mathrm{MAD}=$ maximum angular deviation (see Kirschvink, 1980).

${ }^{\mathrm{c}}$ Principal component without origin is over slightly different treatment range: $95.0(20.0-50.0), 101.0(20.0-75.0), 102.5$ (15.0-30.0), $104.5(0.0-40.0)$. 
APPENDIX B

Directional Data for Hole 758B Lower Jaramillo Polarity Transition

\begin{tabular}{|c|c|c|c|c|c|c|c|c|c|c|}
\hline \multirow[b]{2}{*}{ Sample } & \multirow[b]{2}{*}{$\begin{array}{l}\text { Depth }^{a} \\
\text { (cm) }\end{array}$} & \multirow[b]{2}{*}{$\begin{array}{l}\text { Treatment } \\
\text { range }(\mathrm{mT})\end{array}$} & \multicolumn{4}{|c|}{ With origin } & \multicolumn{4}{|c|}{ Without origin } \\
\hline & & & $n$ & $\begin{array}{c}\text { MAD }^{\mathrm{b}} \\
\text { (degrees) }\end{array}$ & $\begin{array}{l}\text { Declination } \\
\text { (degrees) }\end{array}$ & $\begin{array}{l}\text { Inclination } \\
\text { (degrees) }\end{array}$ & $n$ & $\begin{array}{c}\text { MAD } \\
\text { (degrees) }\end{array}$ & $\begin{array}{l}\text { Declination } \\
\text { (degrees) }\end{array}$ & $\begin{array}{c}\text { Inclination } \\
\text { (degrees) }\end{array}$ \\
\hline 3 & 100.85 & $20.0-40.0+O$ & 4 & 4.3 & 357.5 & 6.4 & 3 & 2.9 & 3.7 & 6.4 \\
\hline 13 & 105.09 & $9.0-25.0+0$ & 6 & 7 & 356.7 & -5.1 & 5 & 9.4 & 350.1 & -1.9 \\
\hline 25 & 110.17 & $9.0-40.0+0$ & 8 & 3 & 359 & 0.2 & 7 & 2.2 & 356.3 & 0.5 \\
\hline 37 & 115.26 & $9.0-30.0+0$ & 7 & 2.4 & 3.3 & 10.7 & 6 & 3.4 & 5.2 & 13 \\
\hline 49 & 120.35 & $9.0-40.0+0$ & 8 & 4 & 4.2 & 5 & 7 & 5.2 & 2.9 & 4.2 \\
\hline 50 & 120.77 & $16.0-30.0+0$ & 5 & 3.4 & 3.3 & 13.4 & 4 & 4.5 & 0.8 & 16.4 \\
\hline 51 & 121.20 & $9.0-30.0+0$ & 7 & 6.6 & 0.6 & 6.4 & 7 & 12.6 & 359.4 & 4.5 \\
\hline 52 & 121.62 & $9.0-25.0+0$ & 6 & 4.6 & 353 & 7.7 & 5 & 12.6 & 354.7 & 1.4 \\
\hline 53 & 122.04 & $12.0-20.0+0$ & 4 & 7.3 & 352.8 & 3.6 & 3 & 3.4 & 8.6 & -0.8 \\
\hline 54 & 122.47 & $0.0-25.0+0$ & 7 & 5.9 & 14 & -3.7 & 6 & 12.3 & 20.6 & -6.8 \\
\hline 55 & 122.89 & $9.0-30.0+0$ & 7 & 6.9 & 359.5 & -3.9 & 6 & 11.2 & 357.2 & -7.9 \\
\hline 56 & 123.32 & $12.0-30.0+0$ & 6 & 4.7 & 358.3 & 9.9 & 5 & 8.1 & 350.7 & 11 \\
\hline 57 & 123.74 & $20.0-40.0+0$ & 5 & 6.7 & 4.6 & -8.9 & 4 & 10.3 & 8.2 & -14.6 \\
\hline 58 & 124.16 & $12.0-40.0+O$ & 7 & 2.2 & 31.1 & 4.6 & 6 & 1.7 & 32.3 & 5.3 \\
\hline 59 & 125.05 & $0.0-25.0+0$ & 7 & 4.1 & 5.8 & -7.7 & 6 & 8.8 & 3.6 & -6.5 \\
\hline 60 & 125.51 & $12.0-25.0+\mathrm{O}$ & 5 & 7.8 & 17.3 & -20 & 4 & 11.4 & 24.5 & -28.9 \\
\hline 61 & 125.97 & $9.0-30.0+0$ & 7 & 6.9 & 9.9 & 0.1 & 6 & 10.9 & 10.4 & -6.4 \\
\hline 62 & 126.43 & $0.0-30.0+0$ & 8 & 6.4 & 354.3 & -0.4 & 7 & 9.7 & 354.8 & -3.7 \\
\hline 63 & 126.89 & $9.0-30.0+0$ & 7 & 10.1 & 1.8 & 8.1 & 6 & 18.8 & 9.5 & 4.8 \\
\hline 64 & 127.35 & $12.0-25.0+O$ & 5 & 10.8 & 5.1 & -12.3 & 4 & 19.1 & 1.8 & -22.2 \\
\hline 65 & 127.82 & $9.0-40.0+0$ & 8 & 9.8 & 17.2 & 8.1 & 7 & 15.2 & 18.3 & 5.4 \\
\hline 66 & 128.28 & $0.0-40.0+0$ & 9 & 10.6 & 20.4 & 0.9 & 8 & 15.3 & 14.6 & 2.7 \\
\hline 67 & 128.74 & $9.0-20.0+0$ & 5 & 5.6 & 20.3 & -5.8 & 4 & 11.1 & 14.2 & -9.4 \\
\hline 68 & 129.20 & $9.0-30.0+0$ & 7 & 7.9 & 36.1 & 5.5 & 6 & 9.9 & 42.9 & 1.9 \\
\hline${ }^{c} 69$ & 129.66 & $16.0-25.0+0$ & 4 & 7 & 27.2 & -4.5 & 3 & 4.8 & 37.5 & 0.3 \\
\hline 70 & 130.12 & $9.0-20.0+0$ & 5 & 8.5 & 20.2 & -8.6 & 4 & 15.9 & 19.4 & -25.9 \\
\hline 91 & 130.58 & $16.0-25.0+0$ & 4 & 9.9 & 14.8 & -6.9 & 3 & 29.8 & 24 & -2 \\
\hline 72 & 131.04 & 9 & 1 & 0 & 23.3 & -3.5 & 1 & 0 & 23.3 & -3.5 \\
\hline 73 & 131.50 & $16.0-30.0+0$ & 5 & 9.5 & 15.9 & 12.3 & 4 & 22 & 16 & 13 \\
\hline 74 & 131.96 & 9 & 1 & 0 & 61.7 & -17.2 & 1 & 0 & 61.7 & -17.2 \\
\hline 75 & 132.42 & $9.0-30.0+0$ & 7 & 11.3 & 17.8 & 2.3 & 6 & 19.7 & 16.3 & 2.9 \\
\hline 76 & 132.89 & $9.0-20.0+0$ & 5 & 3.9 & 345.6 & -18 & 4 & 11.2 & 339.2 & -6.7 \\
\hline 77 & 133.35 & 9 & 1 & 0 & 99.6 & 3 & 1 & 0 & 99.6 & 3 \\
\hline 78 & 133.81 & 9 & 1 & 0 & 135.3 & 21.2 & 1 & 0 & 135.3 & 21.2 \\
\hline${ }^{c} 79$ & 134.27 & $12.0-16.0+O$ & 3 & 5 & 129.6 & 4.9 & 4 & 8.8 & 149.6 & 13.7 \\
\hline 80 & 134.73 & $9.0-25.0+0$ & 6 & 7.1 & 142.7 & -1 & 5 & 8.6 & 143.5 & 5.1 \\
\hline 81 & 135.19 & $9.0-25.0+0$ & 6 & 10.6 & 143.5 & 2.7 & 5 & 20.2 & 137.4 & -3.4 \\
\hline 82 & 135.65 & 9 & 1 & 0 & 108.4 & -14.3 & 1 & 0 & 108.4 & -14.3 \\
\hline 83 & 136.11 & 9 & 1 & 0 & 108.1 & 6.5 & 1 & 0 & 108.1 & 6.5 \\
\hline 84 & 136.57 & 9 & $i$ & 0 & 129.4 & 19.9 & 1 & 0 & 129.4 & 19.9 \\
\hline 85 & 137.03 & $9.0-25.0+0$ & 6 & 6.3 & 135.9 & 12.7 & 5 & 8 & 134.6 & 6.3 \\
\hline 86 & 137.50 & $12.0-30.0+0$ & 6 & 10.4 & 131.9 & 14.9 & 5 & 16.6 & 134.4 & 10.4 \\
\hline 87 & 137.96 & $0.0-20.0+O$ & 6 & 9.8 & 140.4 & 3.2 & 5 & 24.9 & 156.6 & 1.3 \\
\hline$c_{88}$ & 138.42 & $9.0-20.0+0$ & 5 & 5.6 & 154.1 & -0.3 & 6 & 7 & 153.9 & -15 \\
\hline 89 & 138.88 & $9.0-40.0+0$ & 8 & 7.9 & 160.9 & 3.5 & 7 & 7.9 & 166.5 & 3 \\
\hline 90 & 139.34 & $16.0-30.0+O$ & 5 & 3.7 & 177.3 & 2.7 & 4 & 6.6 & 174.8 & 4.4 \\
\hline 91 & 139.80 & $9.0-40.0+0$ & 8 & 4.7 & 185.5 & 11.1 & 7 & 6.4 & 184.9 & 10.1 \\
\hline 92 & 140.26 & $0.0-30.0+0$ & 8 & 5.2 & 175 & 3.7 & 7 & 8.2 & 177.8 & 0.5 \\
\hline 93 & 140.72 & $9.0-40.0+0$ & 8 & 4.6 & 188.1 & 1.4 & 7 & 6.1 & 188.9 & -0.1 \\
\hline 94 & 141.18 & $12.0-40.0+O$ & 7 & 4.9 & 191.5 & -3.8 & 6 & 5.6 & 190.1 & -6.8 \\
\hline 95 & 141.64 & $20.0-30.0+0$ & 4 & 7.4 & 198.1 & 1 & 3 & 15.8 & 201.3 & 9.5 \\
\hline 96 & 142.10 & $12.0-30.0+O$ & 6 & 6.4 & 190.1 & 4.7 & 5 & 8.9 & 198.2 & 7.2 \\
\hline 97 & 142.57 & $9.0-40.0+0$ & 8 & 4.9 & 191.9 & -4 & 7 & 5.9 & 189.8 & -2.8 \\
\hline 98 & 143.03 & $0.0-40.0+0$ & 9 & 5.8 & 194.6 & -11.4 & 8 & 6.6 & 195.9 & -12.7 \\
\hline 99 & 143.49 & $9.0-30.0+0$ & 7 & 7.7 & 183.5 & -8.3 & 6 & 11 & 183 & -2.6 \\
\hline 100 & 143.95 & $12.0-30.0+0$ & 6 & 7.4 & 185.1 & -8.2 & 5 & 9.9 & 177.2 & -7 \\
\hline 101 & 144.41 & 9 & 1 & 0 & 167.6 & -28.5 & 1 & 0 & 167.6 & -28.5 \\
\hline 102 & 144.87 & 9 & 1 & 0 & 188.1 & -6 & 1 & 0 & 188.1 & -6 \\
\hline 103 & 145.33 & $0.0-40.0+0$ & 9 & 3.5 & 190.4 & -2.7 & 8 & 3.7 & 192.7 & -2.2 \\
\hline 104 & 145.79 & $0.0-40.0+0$ & 9 & 2.9 & 186.7 & -1.3 & 8 & 3.4 & 185.7 & -0.1 \\
\hline 105 & 146.25 & $9.0-40.0+0$ & 8 & 2.8 & 193 & -0.9 & 7 & 2.9 & 191.5 & 0.1 \\
\hline 106 & 146.71 & $0.0-40.0+O$ & 9 & 3.4 & 191.4 & -6.7 & 8 & 4.3 & 192.2 & -7 \\
\hline 107 & 147.18 & $16.0-40.0+0$ & 6 & 3.8 & 193.8 & -7.3 & 5 & 5.6 & 193.5 & -9.4 \\
\hline 108 & 147.64 & $9.0-40.0+0$ & 8 & 3.2 & 186.3 & -1.4 & 7 & 3.9 & 184.9 & -2.4 \\
\hline 109 & 148.10 & $9.0-40.0+0$ & 8 & 3.9 & 192.3 & -3.2 & 7 & 5.1 & 191.9 & -4.4 \\
\hline 110 & 148.56 & $12.0-40.0+O$ & 7 & 2.4 & 188.2 & -0.5 & 6 & 2.9 & 188.5 & -1.8 \\
\hline
\end{tabular}

a Relative to the top Section 121-758B-2H-4.

${ }^{b} \mathrm{MAD}=$ maximum angular deviation (see Kirschvink, 1980).

${ }^{c}$ Principal component without origin is over slightly different treatment range: $129.66(20.0-30.0), 130.58(20.0-30.0), 134.27$ (12.0-25.0), 138.42 (9.0-30.0). 